\title{
Thermo-economic optimisation of the polygeneration of Synthetic Natural Gas (SNG), power and heat from lignocellulosic biomass by gasification and methanation
}

\author{
Martin Gassner, François Maréchal \\ Industrial Energy Systems Laboratory, Ecole Polytechnique Fédérale de Lausanne \\ CH - 1015 Lausanne, Switzerland \\ Energy and Environmental Science 5 (2012), 5768-5789, doi:10.1039/clee02867g
}

\begin{abstract}
This paper presents a process model for the polygeneration of Synthetic Natural Gas (SNG), power and heat by catalytic hydrothermal gasification of biomass and biomass wastes in supercritical water. Following a systematic process design methodology, thermodynamic property models and thermo-economic process models for hydrolysis, salt separation, gasification and the separation of $\mathrm{CH}_{4}, \mathrm{CO}_{2}, \mathrm{H}_{2}$ and $\mathrm{H}_{2} \mathrm{O}$ at high pressure are developed and validated with experimental data. Different strategies for an integrated separation of the crude product, heat supply and energy recovery are elaborated and assembled in a general superstructure. The influence of the process design on the performance is discussed for some representative scenarios that highlight the key aspects of the design. Based on this work, a thermo-economic optimisation will allow for determining the most promising options for the polygeneration of fuel and power depending on the available technology, catalyst lifetime, substrate type and plant scale.
\end{abstract}

\section{Nomenclature}

\section{Abbreviations}

CFB Circulating fluidised bed

CHP Combined heat and power

FICFB Fast internally circulating fluidised bed

PSA Pressure swing adsorption

RME Rape methyl esther (biodiesel)

(S)NG (Synthetic) natural gas

TSA Temperature swing adsorption

\section{Greek letters}

$\Delta h^{0} \quad$ Lower heating value $\quad \mathrm{kJ} / \mathrm{kg}$

$\begin{array}{lll}\Delta k^{0} & \text { Exergy value } \quad \mathrm{MJ} / \mathrm{kg}\end{array}$

$\varepsilon \quad$ Energy efficiency $\%$

$\eta \quad$ Exergy efficiency $\%$

$\Phi \quad$ Moisture content $\quad \mathrm{kg}_{\mathrm{H} 2 \mathrm{O}} / \mathrm{kg}_{\text {tot }}$

$\theta \quad$ Molar stage cut

\section{Roman letters}

A Absorption factor

$b \quad$ Cost exponent

C Cost

$\$$ or $\$$ MWh

c Specific cost

$\$ / \mathrm{kW}$ 
$\begin{array}{lll}\tilde{c} & \text { Molar fraction } & \%\end{array}$

$\dot{E} \quad$ Mechanical or electrical power, or exergy $\quad \mathrm{kW}$

$\begin{array}{llr}h & \text { Specific enthalpy } & \mathrm{kJ} / \mathrm{kg}\end{array}$

$\begin{array}{llr}i_{r} \quad \text { Interest rate } & \%\end{array}$

$\dot{m} \quad$ Mass flow $\quad \mathrm{kg} / \mathrm{s}$

$n \quad$ Expected plant lifetime $\quad$ years

$p$ Pressure bar

$\dot{Q} \quad$ Heat $\quad$ kW

$r_{\mathrm{CO} 2 \text {,rem }}$ Carbon dioxide removal in separation $\%$

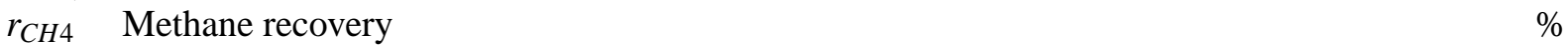

$r_{S / B} \quad$ Steam to dry biomass ratio

$s_{\text {in }, 2} \quad$ Fraction of membrane inlet to stage 2

$T \quad$ Temperature

$t_{a} \quad$ Yearly operating time hours

$W_{s, n} \quad$ Wobbe Index $\quad \mathrm{kWh} \mathrm{Nm}^{-3}$

\section{Subscripts}

ar as received

be break even

bm biomass

c combustion

cg cold gas

$d \quad$ drying

daf dry, ash-free

el electric

$f \quad$ feed

$G R \quad$ grass roots

$G R, d \quad$ depreciated grass roots

$g$ gasification

$m$ methanation

mol molar

$O P \quad$ operation

$P \quad$ production

pr profitability

$q \quad$ heat

ref reference

$s \quad$ steam cycle

$t$ torrefaction

th thermal

tot total

wt weight

\section{Superscripts}

$+\quad$ Material or energy stream entering the system

- Material or energy stream leaving the system

$0 \quad$ Standard conditions (i.e. 1 bar, $25^{\circ} \mathrm{C}$ ) 


\section{Broader context}

As the only natural and renewable resource of highly concentrated carbon, an efficient conversion and use of sustainably available biomass for commodities and energy services is of crucial importance to a future economy.

Compared to the biological production of biofuels that struggle to decompose lignin and hemicellulose, the thermochemical routes allow for a complete conversion of lignocellulosic matter. Due to a higher efficiency than liquid fuel synthesis and the quality of natural gas as a transportation fuel, the production of SNG is an attractive option that could emerge soon on the market.

In Switzerland, the sustainable consumption of natural resources is promoted as the 2000 Watt society challenge, which implies a reduction of the primary energy use by $2 / 3[1]$. This requires both to drastically decrease the final energy use and increase the efficiency of the energy conversion sys- tem. With conservative data for the sustainable biomass potential[2], an optimised and integrated process design as developed in this paper may contribute to reduce the primary energy intensity to 1679 (W year)/year/cap and the $\mathrm{CO}_{2}$ emissions to less than 1.0 ton/year/cap (today: 5.2 ton/year/cap). This scenario reaches a renewable energy share of $72 \%$ with only biomass and hydropower, and does still not consider the potential of solar and wind power.

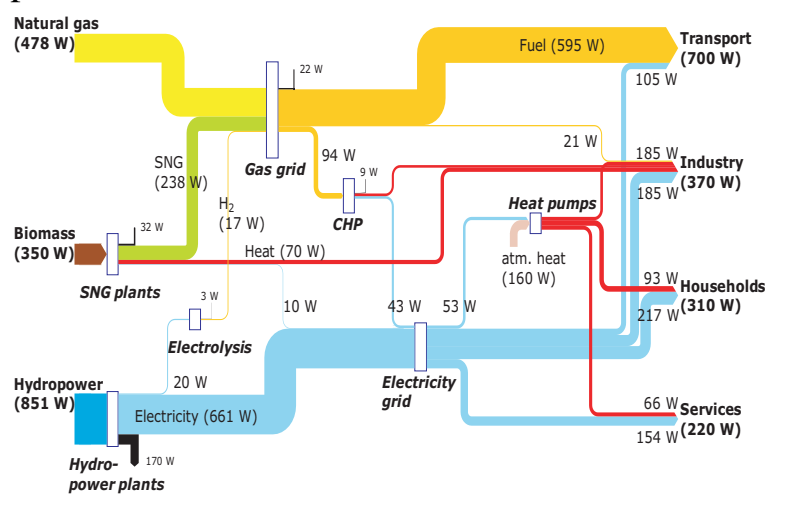

\section{Introduction}

\subsection{SNG production by biomass gasification and methanation}

\subsubsection{Motivation}

The thermochemical conversion of lignocellulosic biomass into Synthetic Natural Gas (SNG) is a promising way to distribute a renewable resource as a versatile energy vector in an existing grid for transportation applications and combined heat and power (CHP) production. By using feedstocks such as sustainably harvested wood, forest and crop residues or municipal and industrial wastes, the production of fuel is decoupled from the one of food and does not rely on intensified agricultural activity, which are the most common reasons for serious sustainability issues of biofuels $[3,4]$. Unlike biological processes that struggle to decompose cellulose and lignin compounds, thermochemical processing thereby allows for a complete conversion of the biomass feedstock by gasification at high temperature. Compared to liquid fuel production, the synthesis of methane is less exothermal and reaches chemical equilibrium, which prevents energy-intense syngas recycling or an important by-production of electricity from residual gas of low-calorific value. The conversion efficiency to SNG is thus inherently high and exceeds the one to liquid fuels by typically $15 \%$-points [5, 6]. Considering that compressed natural gas engines may reach the same efficiencies as diesel engines [7], this makes SNG a very attractive automotive biofuel that benefits from an existing distribution network and allows for high autonomy [8]. Being a priori neutral in fossil $\mathrm{CO}_{2}$-emissions, SNG from sustainably available biomass [9] has the potential for a negative net balance if the by-produced $\mathrm{CO}_{2}$ was sequestrated. $\mathrm{As} \mathrm{CO}_{2}$ has to be removed anyway to distribute the methane in the natural gas grid, sequestration quality can thereby be reached with a smaller efficiencyand cost-penalty than at fossil fuel power plants and is thus potentially cheaper [10].

\subsubsection{Technology development}

In a technology review, Kopyscinski et al. [11] retrace the historical development of technologies for SNG production from coal and dry biomass since the 1950s and summarise commercial projects and 
recent experimental research activities at ECN (Petten, Netherlands), ZSW (Stuttgart, Germany) and PSI (Villigen, Switzerland). While ECN and ZSW focus on gasification technology and gas cleaning, PSI is mainly concerned with the development of a novel fluidised-bed methanation unit that has recently been successfully demonstrated $[12,13]$ at a pilot scale of $1 \mathrm{MW}_{t h, S N G}$ with producer gas from the Fast Internally Circulating Fluidised Bed (FICFB) gasifier [14].

\subsubsection{Flowsheet analysis}

Beginning with the first flowsheeting studies by Mozaffarian and Zwart [15] and Duret et al. [16], several process configurations for thermochemical SNG production by gasification and methanation have recently been investigated in the scientific literature. Van der Meijden et al. [17] have compared the thermodynamic perfomance of three flowsheets based on a commercial slagging entrained flow gasifier, a directly heated circulating fluidised bed (CFB) steam/oxygen gasifier and an indirectly heated CFB gasifier with steam. Juraščík et al. [18] have performed an exergy analysis with respect to gasification pressure and methanation temperatures for a flowsheet based on gasification with external heat supply and assuming chemical equilibrium for gasification and methane synthesis. All these studies consider a dried wood feedstock, fixed-bed methanation (except [16]) and general performance data for the product separation technology (i.e. physical absorption by Selexol $[15,17,18]$ or a membrane cascade [16]).

\subsubsection{Grid integration}

In order to facilitate the implementation of SNG production into existing grids, Heyne et al. [19] have analysed its integration with biomass-based CHP plants and assessed favourable effects due to the possibility for enhancing the electricity cogeneration efficiency. Although strongly dependent on policy and prices, Fahlén and Ahlgren [20] and Difs et al. [21] have found SNG-polygeneration plants to be a very competitive - or even cost-optimal - solution among the biomass gasification alternatives in a district heating system. Toonssen et al. [22] have further assessed the efficiency of decentralised CHP from SNG with a combined fuel cell/heat pump system.

\subsubsection{LCA}

Based on the life cycle analysis (LCA) of Felder and Dones [23], Zah et al. [24] have compared the environmental impact of SNG with other biofuels and assessed a reduction down to $30 \%$ of the greenhouse gas emission of petrol without any significant penalty in other impact categories. Their data is used in the Swiss LCA database ecoinvent [25]. More recently, Steubing et al. [26] confirm the environmental benefit in a LCA for a 7.5 MW demonstration project.

\subsubsection{Optimal process design}

The comparison of SNG production processes can not only be based on the efficiencies achieved in pilot plants. It can not be based neither on simulation results that are reported with different assumptions. The development of a sound process design requires in addition to account not only for the thermodynamic efficiency of the integrated plant, but also for the trade-off between the investment for the equipment and the operating expenses that are related to the design.

In an attempt to perform a systematic process design and optimisation of SNG production, our work has focussed on the development of a thermo-economic process model for a superstructure of candidate technology including several options for drying, gasification and product separation [5]. Based on a conceptual process design methodology that combines process modelling, integration and optimisation [27, 28], this model has been used to perform a thermodynamic and exergy analysis for different gasifiers, to analyse the enhanced production of SNG by integration of an electrolysis unit and to study the prospects of integrating the reaction and separation subsystems of a plant [10, 29, 30]. In addition, Gerber et al. [31] have integrated LCA in the model to systematically include environmental criteria 


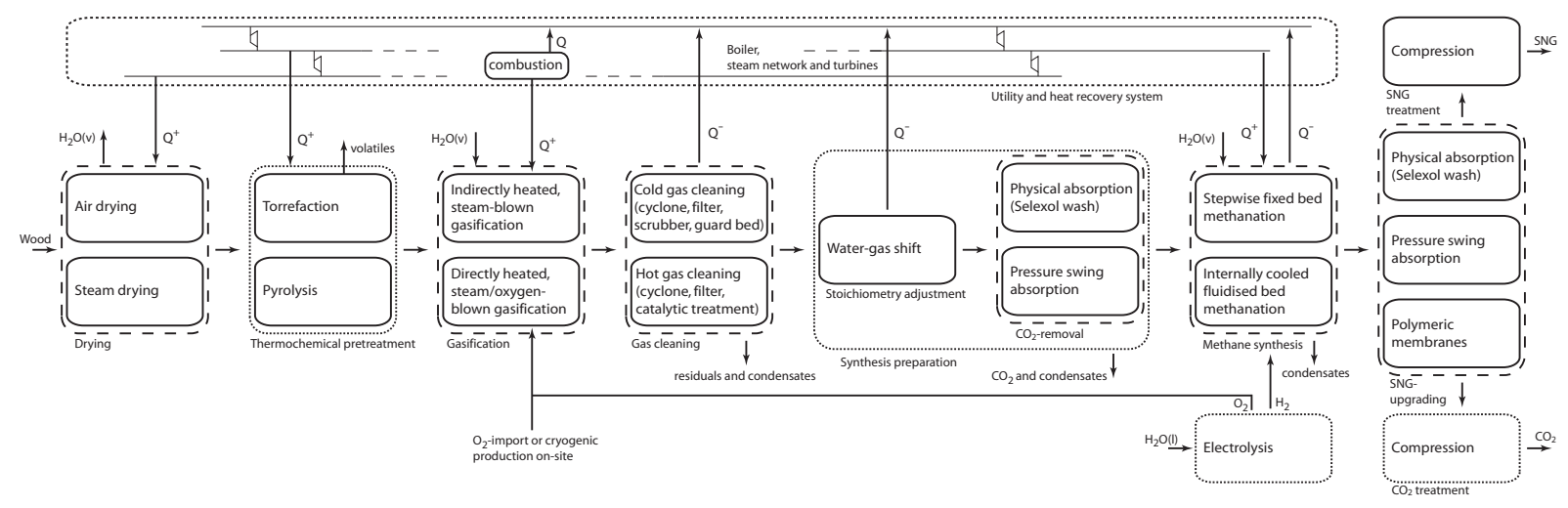

Figure 1: Process superstructure including main process streams without recycling loops. Dashed lines assemble investigated alternatives for different process sections and dotted lines indicate optional units [5].

in the process development and allow for a environomic (i.e. energetic, economic and environmental) optimisation of the design.

Table 1 provides a general overview on the modelled flowsheets and/or assumed performances for SNG production by wood gasification and methanation in the literature. This comparison highlights the considerable differences with respect to the thermo-economic performance. In particular, the low efficiencies assumed in LCA applications result in a significant underestimation of the potential benefits of the technology.

\subsection{Objective}

As indicated by the superstructure of candidate technology for SNG production depicted in Figure 1, thermochemical production of fuel from biomass proceeds through multiple conversion steps for which several technological options are available[5]. This results in a multitude of potential process configurations whose technologies adapt and integrate differently with each other. The product yields and thermo-economic characteristics of all these alternatives are further expected to change with scale, and the choice of the optimal plant configuration is dependent on the prevailing or projected economic conditions in which the relative value of both capital and the multiple energy services may change.

Based on the previously developed process model and the design methodology [5, 27], the objective of this paper is to thermo-economically optimise, evaluate and compare the design options for the production of SNG from lignocellulosic biomass, and thereby demonstrate the benefit of a comprehensive process systems approach for the production of synthetic fuels from renewable feedstocks. To do so, we propose to systematically optimise the performance of all possible process configurations included in the superstructure and identify the most promising technology sets and the corresponding operating conditions with respect to plant scale and the economic environment. Unlike previous studies in the field of fuel production from biomass that have carried out this kind of task by defining some typical flowsheet scenarios by hand, we thereby attempt a general typefaction of the candidate technology by multi-objective optimisation.

\section{Methodology}

In order to systematically address the typefaction and optimisation of the candidate technology and process configurations, the present paper follows the approach illustrated in Figure 2. In a first step, all potentially adequate technology routes are identified from the process superstructure of Figure 1 (Section 3). For each of these candidate configurations, a set of thermo-economically optimal flowsheets is then generated by multi-objective optimisation of their design with respect to adequate performance 
Table 1: Synopsis of modelled flowsheets and/or assumed performances for SNG production by wood gasification and methanation in the scientific literature. Data for entries 'n.a.' are not available. See nomenclature for variable definitions.

\begin{tabular}{|c|c|c|c|c|c|c|c|c|c|c|c|c|c|c|}
\hline \multirow[t]{2}{*}{ Ref. } & \multirow{2}{*}{$\begin{array}{l}\text { Process } \\
\text { configuration }\end{array}$} & \multirow{2}{*}{$\begin{array}{c}\text { Feed } \\
\Phi_{\text {feed }} \\
\%_{w t} \\
\end{array}$} & \multicolumn{4}{|c|}{ Operating conditions } & \multicolumn{2}{|c|}{ Grid spec. } & \multicolumn{5}{|c|}{ Efficiencies $^{\mathrm{a}}$} & \multirow{2}{*}{$\begin{array}{c}\text { Investment } \\
C_{G R} \\
\mathrm{M} \$ \text { at } \mathrm{MW}_{\text {in }}\end{array}$} \\
\hline & & & $\begin{array}{l}\Phi_{g} \\
\%_{w t}\end{array}$ & $\begin{array}{l}p_{g} \\
\text { bar }\end{array}$ & $\begin{array}{l}T_{g} \\
{ }^{\circ} \mathrm{C} \\
\end{array}$ & $\begin{array}{l}p_{m} \\
\text { bar }\end{array}$ & $\begin{array}{c}\tilde{c}_{C H 4} \\
\%\end{array}$ & $\begin{array}{c}p_{\text {grid }} \\
\text { bar }\end{array}$ & $\varepsilon_{c g}$ & $\varepsilon_{S N G}$ & $\begin{array}{r}\varepsilon_{e l} \\
\%\end{array}$ & $\varepsilon_{t h}$ & $\varepsilon_{\text {chem }}{ }^{\mathrm{b}}$ & \\
\hline \multirow[t]{3}{*}{ [15] } & \multicolumn{14}{|c|}{ no drying, fixed bed meth., Selexol wash, steam cycle with headers at 40 and 0.05 bar } \\
\hline & $\begin{array}{l}\text { (a) ind. heated CFB } \\
\text { gas., cold gas clean. }\end{array}$ & 15 & 15 & 1 & n.a. & 15 & $87.7^{\mathrm{c}}$ & 15 & n.a. & 67.0 & -2.9 & - & 61.9 & 44.9 at 100 \\
\hline & $\begin{array}{l}\text { (b) dir. heated CFB- } \\
\mathrm{O}_{2} \text { gas., warm gas } \\
\text { clean. }\end{array}$ & 15 & 15 & 15 & n.a. & 15 & $87.6^{\mathrm{c}}$ & 15 & $83.0^{\mathrm{b}}$ & 66.3 & -2.7 & - & 61.6 & 48.2 at 100 \\
\hline \multirow[t]{2}{*}{ [16] } & \multicolumn{14}{|c|}{ no drying, fluid. bed meth., 3-stage membrane sep., steam cycle with headers at 120,12 and 0.04 bar } \\
\hline & $\begin{array}{l}\text { ind. heated FICFB } \\
\text { gas., cold gas clean. }\end{array}$ & 0 & 0 & 1 & 850 & 60 & 96.1 & 48 & 82.3 & 59.7 & -0.8 & - & 58.3 & n.a. \\
\hline \multirow[t]{4}{*}{ [17] } & \multicolumn{14}{|c|}{ no drying, fluidised bed meth., Selexol wash, steam cycle with headers at 60 and 10 bar $^{\mathrm{d}}$} \\
\hline & $\begin{array}{l}\text { (a) ind. heated Milena } \\
\text { gas., cold gas clean. }\end{array}$ & 15 & 15 & 1 & 850 & 7 & 90.7 & 30 & 80.0 & 70.3 & $-2.1^{\mathrm{b}}$ & - & 66.6 & n.a. \\
\hline & $\begin{array}{l}\text { (b) dir. heated CFB- } \\
\mathrm{O}_{2} \text { gas., warm gas } \\
\text { clean. }\end{array}$ & 15 & 15 & 10 & 850 & 10 & 89.9 & 30 & 73.7 & 63.5 & $-3.2^{\mathrm{b}}$ & - & 57.9 & n.a. \\
\hline & $\begin{array}{l}\text { (c) torrefaction, en- } \\
\text { trained flow gas., } \\
\text { warm gas clean. }\end{array}$ & 15 & 15 & 30 & 1300 & 30 & 90.5 & 30 & $70.6^{\mathrm{b}, \mathrm{e}}$ & 52.7 & $1.0^{\mathrm{b}}$ & - & 54.5 & n.a. \\
\hline \multirow[t]{3}{*}{ [19] } & \multicolumn{14}{|c|}{$\begin{array}{l}\text { ind. heated CFB gas., cold gas clean., stepwise chem. absorption (MEA) before final meth., } \mathrm{H}_{2} \text {-recyling to meth., } \\
\text { steam cycle with headers at } 140,27.5,18.0,6.2,3,0.76 \text { and } 0.34 \text { bar }\end{array}$} \\
\hline & (a) air drying & 50 & 20 & 1 & 850 & 10 & 97.2 & 10 & n.a. & $60.7^{\mathrm{b}}$ & $5.4^{\mathrm{b}}$ & - & 71.2 & n.a. \\
\hline & (b) steam drying & 50 & 20 & 1 & 850 & 10 & 97.2 & 10 & n.a. & $60.7^{\mathrm{b}}$ & $4.8^{\mathrm{b}}$ & $8.8^{\mathrm{b}}$ & 72.6 & n.a. \\
\hline$[20,21$ & \multicolumn{14}{|c|}{ drying (unspec. technology), dir. heated CFB- $\mathrm{O}_{2}$ gas., Selexol wash, steam cycle with headers at $90,40,15$ and 5.5 bar } \\
\hline [20] & & 50 & n.a. & $25^{\mathrm{b}}$ & n.a. & $25^{\mathrm{b}}$ & n.a. ${ }^{\mathrm{c}}$ & 25 & n.a. & 72.0 & -4.0 & 24.0 & 74.4 & 243 at 240 \\
\hline [21] & & 50 & n.a. & $25^{\mathrm{b}}$ & n.a. & $25^{\mathrm{b}}$ & n.a. ${ }^{\mathrm{c}}$ & 25 & n.a. & 69.0 & -4.0 & 23.0 & 71.0 & 243 at 240 \\
\hline \multirow[t]{2}{*}{ [24] } & \multicolumn{14}{|c|}{ drying (unspec. technology), ind. heated FICFB gas., cold gas cleaning, methanation, PSA, no steam cycle. Data from [23] is used. } \\
\hline & $\begin{array}{l}\text { Ecoinvent database } \\
{[25]}\end{array}$ & 47 & 15 & 1 & 850 & 2 & 96.0 & 50 & 73.0 & $51.1^{\mathrm{f}}$ & -5.0 & - & 42.3 & n.a. \\
\hline \multirow[t]{2}{*}{ [26] } & \multicolumn{14}{|c|}{$\begin{array}{l}\text { drying (unspec. technology), ind. heated FICFB gas., cold gas cleaning, fluid. bed methanation, chem. absorption (MEA), } \\
\text { no steam cycle. } 1 / 3 \text { of the clean producer gas is burnt in a gas engine for CHP to balance the plant's power requirement. }\end{array}$} \\
\hline & $\begin{array}{l}\text { LCA of } 7.5 \text { MW } \\
\text { demo plant }\end{array}$ & 50 & 20 & 1 & 850 & n.a. & 96.0 & 5 & n.a. & 39.0 & - & 19.0 & 57.9 & n.a. \\
\hline \multirow[t]{4}{*}{ [5] } & \multicolumn{14}{|c|}{ air drying, fluid. bed meth., $\mathrm{H}_{2}$ - after $\mathrm{CO}_{2}$-sep. and recycling to meth., steam cycle with headers at $14.9,4.76,1.98$ and 0.02 bar } \\
\hline & $\begin{array}{l}\text { (a) ind. heated FICFB } \\
\text { gas., cold gas clean., } \\
\text { TSA, PSA }\end{array}$ & 50 & 20 & 1 & 850 & 5.5 & 96.0 & 50 & 78.5 & 66.0 & 2.6 & - & 70.5 & 23.3 at 20 \\
\hline & $\begin{array}{l}\text { (b) dir. heated CFB- } \\
\mathrm{O}_{2} \text { gas., cold gas } \\
\text { clean., Selexol wash }\end{array}$ & 50 & 20 & 15 & 800 & 15 & 96.0 & 50 & 85.0 & 73.7 & -0.2 & - & 73.5 & 17.9 at 20 \\
\hline & $\begin{array}{l}\text { (c) dir. heated CFB- } \\
\mathrm{O}_{2} \text { gas., hot gas } \\
\text { clean., Selexol wash }\end{array}$ & 50 & 20 & 15 & 800 & 15 & 96.0 & 50 & 85.0 & 73.8 & 1.6 & - & 76.6 & 17.8 at 20 \\
\hline \multicolumn{15}{|c|}{ This work, after optimisation based on [5]. For scaling and details on the process configurations, see Tables 7,9 and Figures $9,11}$. \\
\hline & \multirow[t]{4}{*}{ FICFB gasification } & 50 & 10 & 1 & 850 & 4.4 & 96.0 & 50 & $81.4^{\mathrm{g}}$ & 69.3 & 3.7 & - & 75.9 & 23.8 at 20 \\
\hline & & 50 & 14 & 1 & 850 & 12 & 96.0 & 50 & $76.6^{\mathrm{g}}$ & 65.9 & 1.8 & 16.9 & 78.7 & 21.9 at 20 \\
\hline & & 50 & 11 & 1 & 850 & 4.4 & 96.0 & 50 & $81.2^{\mathrm{g}}$ & 69.1 & 4.0 & - & 76.2 & 102.5 at 100 \\
\hline & & 50 & 12 & 1 & 850 & 17 & 96.0 & 50 & $80.8^{\mathrm{g}}$ & 68.9 & 0.5 & 16.3 & 79.0 & 92.7 at 100 \\
\hline & \multirow[t]{4}{*}{ CFB- $\mathrm{O}_{2}$ gasification } & 50 & 11 & 29 & 800 & 29 & 96.0 & 50 & 87.0 & 75.0 & 2.6 & - & 79.6 & 16.6 at 20 \\
\hline & & 50 & 10 & 30 & 800 & 30 & 96.0 & 50 & 87.1 & 68.1 & 3.0 & 19.8 & 84.6 & 15.0 at 20 \\
\hline & & 50 & 11 & 29 & 800 & 29 & 96.0 & 50 & 87.0 & 75.1 & 2.6 & - & 79.6 & 50.5 at 100 \\
\hline & & 50 & 10 & 30 & 800 & 30 & 96.0 & 50 & 87.2 & 75.4 & 1.4 & 13.8 & 85.8 & 52.1 at 100 \\
\hline
\end{tabular}

a $\varepsilon_{c g}$ : cold gas efficiency of gasifier, others as defined in Section 2.2.1. All values are based on the lower heating value of the dry feedstock

$\mathrm{b}$ implicitely reported or recalculated from other data

c [15]: $W_{s, n}=12.1 \mathrm{kWh} \mathrm{Nm}^{-3}$ (G-gas quality); [20, 21] and others: $W_{s, n}>13.3 \mathrm{kWh} \mathrm{Nm}^{-3}$ (H-gas quality)

$\mathrm{d}$ a third steam usage level is not reported but probably used

e including torrefaction

f $18 \%$ of the gross SNG yield $\left(\varepsilon_{S N G}=62.0 \%\right)$ is combusted to produce steam for gasification. This is contradictory to all flowsheeting and process design studies that assess a sufficient amount of excess heat to cover all internal heat demands.

$\mathrm{g}$ calculated by substitution due to process integration: $\varepsilon_{c g}=\left(\mathrm{PG}_{\text {gross }}-\mathrm{PG}_{c}-\mathrm{DG}_{c}\right) /\left(\right.$ wood+biodiesel), with $\mathrm{PG}_{\text {gross }}$ : gross output of cold\&cleaned producer gas, $\mathrm{PG}_{c}$ : cold\&cleaned producer gas fed to combustion chamber, $\mathrm{DG}_{c}$ : depleted gas from $\mathrm{CO}_{2}$-separation fed to combustion chamber 


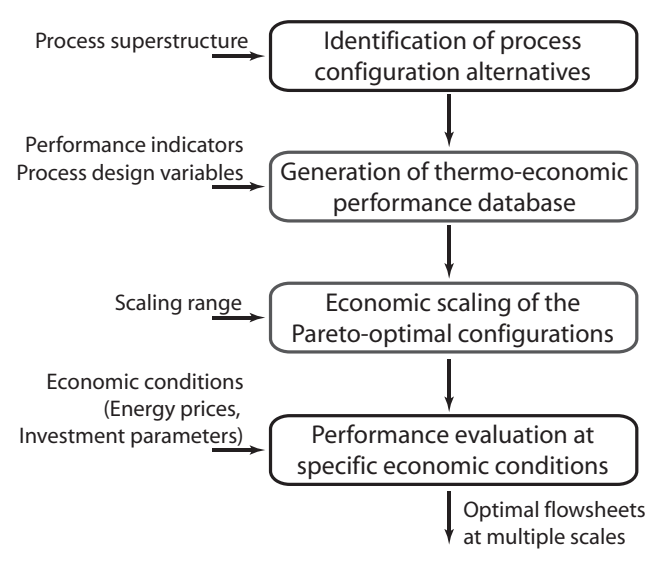

Figure 2: Typefaction sequence.

indicators (Section 4). This database of Pareto-optimal flowsheets is then scaled (Section 5), which finally allows for systematically evaluating the thermo-economic performance of all technology routes and identifying the optimal configurations with respect to different economic conditions at multiple scales (Section 6). Compared to the conventional optimisation of a flowsheet, this multi-dimensional optimisation methodology has the remarkable advantage that the time-consuming optimisation step does not need to be repeated if the economic conditions, the production setting and/or the scale change. Instead, the optimal plant configuration can be found by a simple query in a database, which is provided in the electronic supplementary information. This data contains all the information required to reevaluate the process designs in another economic context.

\subsection{Conceptual process design by modelling and optimisation}

The thermo-economic process model has been developed following a systematic methodology for the conceptual design of thermochemical production of fuels from biomass [5, 27]. Through an analysis of the raw material characteristics, product specifications and feasible production pathways, suitable technology for the process unit operations and energy recovery are identified and assembled in a process superstructure. A decomposition-based modelling approach is then adopted to systematically develop candidate flowsheets. First, the thermochemical conversions and the heat and power requirements of the process units are computed in energy-flow models that are developed in flowsheeting software [32]. These models have been reconciled with experimental data[5] and are valid for the purpose of a conceptual design within the range of the operating conditions considered here. The combined mass- and energy integration is then performed by mixed integer linear programming, in which both the material flows defined by the superstructure and the heat cascade - that represents the heat exchanger network act as constraints [28]. Considering waste and selected intermediate product streams as candidate fuels to supply the required heat, the combined SNG, heat and power production is optimised with respect to a weighted yield of the products. For the so-determined flowsheet, all the equipment is rated with design heuristics[33] and data from laboratory and pilot plants. Based on this rating, the capital investment required to meet the thermodynamic design target is then estimated with standard engineering procedures[33] and available data from pilot plants[5]. This model decomposition is particularly appropriate for conceptual process design since it allows for efficiently generating a set of optimal process configurations with an evolutionary, multi-objective optimisation algorithm. 


\subsection{Performance indicators}

\subsubsection{Thermodynamic performance}

Throughout the analysis, the thermodynamic performance of process flowsheets is discussed in terms of the conversion efficiencies of the products, i.e. SNG (1), electricity (2) and heat (3):

$$
\begin{aligned}
\varepsilon_{S N G} & =\frac{\Delta h_{S N G}^{0} \dot{m}_{S N G}^{-}}{\Delta h_{b m}^{0} \dot{m}_{b m, d a f}^{+}+\Delta h_{R M E}^{0} \dot{m}_{R M E}^{+}} \\
\varepsilon_{e l} & =\frac{\dot{E}^{-}}{\Delta h_{b m}^{0} \dot{m}_{b m, d a f}^{+}+\Delta h_{R M E}^{0} \dot{m}_{R M E}^{+}} \\
\varepsilon_{t h} & =\frac{\dot{Q}^{-}}{\Delta h_{b m}^{0} \dot{m}_{b m, d a f}^{+}+\Delta h_{R M E}^{0} \dot{m}_{R M E}^{+}}
\end{aligned}
$$

and the overall energy $\varepsilon$, exergy $\eta$ and 'chemical' $\varepsilon_{c h e m}$ efficiencies defined as, respectively:

$$
\begin{gathered}
\varepsilon=\frac{\Delta h_{S N G}^{0} \dot{m}_{S N G}^{-}+\dot{E}^{-}+\dot{Q}^{-}}{\Delta h_{b m}^{0} \dot{m}_{b m, d a f}^{+}+\Delta h_{R M E}^{0} \dot{m}_{R M E}^{+}+\dot{E}^{+}} \\
\eta=\frac{\Delta k_{S N G}^{0} \dot{m}_{S N G}^{-}+\dot{E}^{-}+\dot{E}_{q}^{-}}{\Delta k_{b m}^{0} \dot{m}_{b m, d a f}^{+}+\Delta k_{R M E}^{0} \dot{m}_{R M E}^{+}+\dot{E}^{+}} \\
\varepsilon_{c h e m}=\frac{\Delta h_{S N G}^{0} \dot{m}_{S N G}^{-}+\frac{1}{\eta_{N G C C}} \frac{\Delta h_{S N G}^{0}}{\Delta k_{S N G}^{0}}\left(\dot{E}^{-}+\frac{\dot{E}_{q}^{-}}{\eta_{H P}}\right)}{\Delta h_{b m}^{0} \dot{m}_{b m, d a f}^{+}+\Delta h_{R M E}^{0} \dot{m}_{R M E}^{+}}
\end{gathered}
$$

in which $\Delta h^{0}$ and $\Delta k^{0}$ designate the dry lower heating and exergy values and $\dot{m}$ the mass flow of SNG, the main biomass (bm) substrate and biodiesel (RME) that is burnt after its use as solvent for scrubbing. $\Delta h^{0}$ and $\Delta k^{0}$ of the raw materials are determined with correlations for the dry, ash-free (daf) substrates $[34,35] . \dot{E}$ represents the net balance of electrical power consumed on-site and externally for oxygen production in a cryogenic plant $\left(1080 \mathrm{~kJ}_{e l} \mathrm{~kg}_{O 2}^{-1}\right)[36$, (App. A) $] . \dot{Q}$ and $\dot{E}_{q}$ refer to heat and its exergy value [29], and the superscripts ${ }^{-}$and ${ }^{+}$to produced and consumed services, respectively. While only the positive value of $\dot{E}$ occurs either in the numerator or denominator of Eqns. (4) and (5), net electricity consumptions are assessed by negative values of $\dot{E}^{-}$in Eqns. (2) and (6).

The overall energy and exergy indicators $\varepsilon$ and $\eta$ provide a strictly physical measure of the energy conversion and its quality degradation. Yet, they do not satisfactorily assess the value of the products with respect to competing technologies and the efficiency of their further conversion into final energy services [37]. The technical value of all products are therefore assessed in terms of the weighted fuelequivalent efficiency $\boldsymbol{\varepsilon}_{\text {chem }}$, in which the net electricity balance and heat cogeneration is substituted by the equivalent amount of (synthetic) natural gas that is consumed or saved in reference technology. Aiming at a consistent weighting with efficient state-of-the-art technology, electricity is represented by a natural gas combined cycle (NGCC), and heat by electricity-driven heat pumps (HP), both with an exergy efficiency of $\eta_{N G C C}=\eta_{H P}=55 \%$. This corresponds to an energy efficiency of $\varepsilon_{N G C C}=57 \%$ and performance coefficients of 3.1 and 1.6 for electricity- and gas driven heat pumps in a district heating network with supply and return temperatures of 110 and $70^{\circ} \mathrm{C}$, respectively. From an energy systems perspective, this substitution is legitimate and leads to a consistent and technologically reasonable appraisal of the different energy vectors [38].

\subsubsection{Economic performance}

The economic performance assessment of a process configuration is based on the specific investment costs $c_{G R}$ normalised with the main biomass substrate $\left[\$ \mathrm{~kW}_{b m}^{-1}\right]$ :

$$
c_{G R}=\frac{C_{G R}}{\Delta h_{b m}^{0} \dot{m}_{b m, d a f}^{+}}
$$


Table 2: Assumptions for process economics with green prices for electricity, SNG and industrial heat. The sensitivity of the economically optimal plant with respect to the alternative prices of Table 8 is analysed in Section 6 .

\begin{tabular}{llcc}
\hline Parameter & & Unit & Value \\
\hline Currency & & US Dollars & $1302^{\mathrm{a}}$ \\
Marshall \& Swift index & $i_{r}$ & - & 6 \\
Interest rate & $n$ & $\%$ & 15 \\
Discount period & $t_{a}$ & years & 7690 \\
Yearly operating time & & $\mathrm{h}$ & $4^{\mathrm{c}}$ \\
Operators & & $\$$ yer shift $^{-1}$ & $600^{\prime} 000$ \\
Operator salary & & $\%$ of $_{G R}$ year $^{-1}$ & 5 \\
Maintenance cost & & & \\
Prices & $C_{O 2}$ & $\$ \mathrm{~kg}^{-1}$ & variable[39] \\
- Oxygen & $C_{R M E}$ & $\$ \mathrm{MWh}^{-1}$ & 105 \\
- Biodiesel & $C_{b m}$ & $\$ \mathrm{MWh}^{-1}$ & 33 \\
- Wood $\left(\Phi_{b m}=50 \%\right)$ & $C_{e l}$ & $\$ \mathrm{MWh}^{-1}$ & 180 \\
- Electricity $(\mathrm{green})$ & $C_{S N G}$ & $\$ \mathrm{MWh}^{-1}$ & 120 \\
- SNG & $C_{q}$ & & 80 \\
- Industrial heat $\left(110 / 70^{\circ} \mathrm{C}\right)$ & &
\end{tabular}

a Average of year 2006

${ }^{\mathrm{b}}$ Full time operation requires three shifts per day. With a working time of five days per week and 48 weeks per year, one operator per shift corresponds to 4.56 employees

${ }^{\mathrm{c}}$ For a plant size of $20 \mathrm{MW}_{\text {th,biomass }}$. For other production scales, an exponent of 0.7 with respect to plant capacity is used

in which $C_{G R}[\$]$ represents the total investment from 'grass roots' determined from the detailed equipment rating and costing in the thermo-economic process model [5].

The total costs $C_{t o t}\left[\$ \mathrm{MWh}_{b m}^{-1}\right]$ for the conversion of one unit of biomass to SNG, power and heat is calculated by discounting the investment with the capital recovery factor to $C_{G R, d}$ and adding the plant's operating costs $C_{O P}$ that includes the expenses for the feedstock, auxiliary material (i.e. biodiesel (RME) and oxygen), labour and maintenance:

$$
C_{t o t}=C_{G R, d}+C_{O P}
$$

with:

$$
\begin{aligned}
C_{G R, d}= & \frac{i_{r}\left(1+i_{r}\right)^{n}}{\left(1+i_{r}\right)^{n}-1} \cdot \frac{C_{G R}}{t_{a} \Delta h_{b m}^{0} \dot{m}_{b m, d a f}^{+}} \\
C_{O P}= & C_{b m}+\frac{\Delta h_{R M E}^{0} \dot{m}_{R M E}^{+} C_{R M E}+\dot{m}_{O 2}^{+} C_{O 2}}{\Delta h_{b m}^{0} \dot{m}_{b m, d a f}^{+}} \\
& +\frac{C_{\text {salaries }}+0.05 C_{G R}}{t_{a} \Delta h_{b m}^{0} \dot{m}_{b m, d a f}^{+}}
\end{aligned}
$$

for which the definitions and default values of the parameters and prices are summarised in Table 2 .

Accounting for the earnings from selling SNG and the coproduced power and heat, the overall economic performance is expressed by the maximum acceptable biomass cost for the plant to break even $C_{b m, b e}\left[\$ \mathrm{MWh}_{b m}^{-1}\right]$, i.e.:

$$
C_{b m, b e}=C_{b m, p r}+C_{b m}
$$

with:

$$
\begin{aligned}
C_{b m, p r} & =\left(\varepsilon_{S N G} C_{S N G}+\varepsilon_{e l} C_{e l}+\varepsilon_{t h} C_{q}\right) \cdot f_{R M E}-C_{t o t} \\
f_{R M E} & =\frac{\Delta h_{b m}^{0} \dot{m}_{b m, d a f}^{+}+\Delta h_{R M E}^{0} \dot{m}_{R M E}^{+}}{\Delta h_{b m}^{0} \dot{m}_{b m, d a f}^{+}} \gtrsim 1
\end{aligned}
$$


in which $f_{R M E}$ is introduced to explicitely highlight the influence of the conversion efficiencies (1)-(3) on the net profit $C_{b m, p r}$ that is obtained from the conversion of $1 \mathrm{MWh}$ of biomass if SNG, electricity and heat are sold at prices of $C_{S N G}, C_{e l}$ and $C_{q}$, respectively.

The cost formulation of Equations (8)-(13) that is normalised with respect to the conversion of one unit of biomass provides a coherent assessement of the overall process economics. It is worthwhile to note that this would not be the case if the economic performance was based on the production cost for one unit of SNG, in which the benefits from selling the coproducts (heat and power) are accounted by negative contributions ${ }^{3}$. Although convenient for a single product, such an assymetric assessement is misleading in a polygeneration context since it might suggest to enhance the coproduction of the (sold) by-products to the expense of the main one[37].

\subsection{Multi-objective optimisation}

Multi-objective optimisation techniques have been introduced in the conceptual design of energy conversion systems in order to provide an enlarged set of candidate solutions to a design problem that is characterised by several conflicting objectives such as efficiency, cost and environmental impact. For instance, such approaches have been applied to a benchmark cogeneration problem [40-42], district heating networks [43], fuel cell systems [44, 45], natural gas combined cycles [46], and biomass-based co- and polygeneration of fuels, heat and power [27, 28, 31, 47, 48]. Compared to the introduction of constraints in single-objective mathematical programming and global optimisation [48-50], evolutionary algorithms do not need to compute the derivatives, which makes them suitable and robust for complex non-linear and non-continuous optimisation problems of black-box models. In this work, a multi-modal, evolutionary algorithm based on crossover and mutation techniques has been applied[43, 51]. In this algorithm, the continuous variables are not coded as binary genes but are explicitly treated as continuous variables. The algorithm solves the multi-objective optimisation by using the dominancy criteria to select the members of the parents' population. In order to maintain the diversity in the Pareto set, clustering methods are used to generate Pareto subsets. Populations in Pareto subsets are then preferably used for reproduction.

\section{Optimisation problem formulation}

\subsection{Production setting}

Thermochemical conversion processes are highly integrated installations that can generate several products and energy services from biomass. The relative amounts of these products are adjusted in the process design through the selection of technologies and operating conditions to provide the optimal mix. In particular, the best configuration for a specific production setting is dependent on local heat cogeneration opportunities, biomass availability and economic boundary conditions such as energy prices and interest rates. In order to take these specific conditions into consideration, all candidate configurations are optimised at a reference scale of $20 \mathrm{MW}_{t h, b m}$ without and with considering industrial heat cogeneration at $110^{\circ} \mathrm{C}\left(70^{\circ} \mathrm{C}\right.$ return $)$. With the generated database at the reference conditions of Table 2 , it is then possible to investigate the influence of process scale and energy prices and determine the optimal plants at specific local conditions. For the entire analysis, wood with the properties of Table 3 is considered as raw material. SNG at $96 \%$ mol $\mathrm{CH}_{4}$ is delivered dry to the grid at $25^{\circ} \mathrm{C}$ and 50 bar.

\subsection{Process configuration alternatives}

Based on the developed process model for the superstructure depicted on Figure 1 [5], all possible technology combinations for SNG production by gasification and methanation are considered in the optimi-

\footnotetext{
${ }^{3}$ If nevertheless desired, this cost can be obtained from: $C_{P, S N G}=C_{S N G}-\left(\Delta h_{b m}^{0} \dot{m}_{b m, d a f}^{+}\right) /\left(\Delta h_{S N G}^{0} \dot{m}_{S N G}^{-}\right) C_{b m, p r}$ $\left[\$ \mathrm{MWh}_{S N G}^{-1}\right]$.
} 
Table 3: Proximate and ultimate analysis of the wood feedstock.

\begin{tabular}{|c|c|c|c|}
\hline \multicolumn{2}{|c|}{ Proximate analysis } & \multicolumn{2}{|c|}{ Ultimate analysis } \\
\hline$\overline{\Delta h^{0 \mathrm{a}}}$ & $18.6 \mathrm{MJ} \mathrm{kg}_{\text {daf }}^{-1}$ & $\mathrm{C}$ & $51.09 \%_{w t}$ \\
\hline$\Delta k^{0 \mathrm{~b}}$ & $20.9 \mathrm{MJ} \mathrm{kg}_{\text {daf }}^{-1}$ & $\mathrm{H}$ & $5.75 \%_{w t}$ \\
\hline Moisture $\left(\Phi_{\text {feed }}\right)$ & $50.0 \%_{w t, a r}$ & $\mathrm{O}$ & $42.97 \%_{w t}$ \\
\hline Ash content & $0.6 \%_{w t, d r y}$ & $\mathrm{~N}$ & $0.19 \%{ }_{w t}$ \\
\hline
\end{tabular}

a $\Delta h^{0}$ is calculated according to [34] on dry, ash-free basis and is thus independent on moisture content.

b Chemical exergy $\Delta k^{0}$ is calculated according to [35].

sation. Detailed flowsheets for the unit processes of Figure 1 are available in [37, App. A]. A summary of the decision variables and fixed key operating conditions is detailed in Table 4.

Overall, the typefaction covers 60 (20 FICFB, 16 CFB-O2 and 2.12 pressurised FICFB) technology combinations that are individually optimised for operation with and without industrial heat cogeneration. Since the applied evolutionary algorithm $[43,51]$ does not feature a convergence criterion, the optimisations are stopped after 10'000 iterations. The large computational effort has been managed by parallel computing on the EPFL pleiades cluster [? ] in approximately 10'000 CPU hours.

\subsubsection{Drying and thermochemical pretreatment}

Both air and steam drying technologies are optimised with respect to the residual moisture content and the temperature of the drying medium. In case of steam drying, operating pressure is also used as a decision variable since it determines the temperature at which the latent heat of the vapourised moisture is recovered. Among the thermochemical pretreatment options, torrefaction is only considered in connection with indirectly heated gasification since the released volatiles can be burnt to supply heat for gasification. Pyrolysis is not included in the candidate configurations since the scale-up of the investigated screw conveyor pyrolysis unit is expected to be very costly $[5,52]$.

\subsubsection{Gasification}

For gasification, indirectly heated, fluidised bed FICFB technology and directly heated, pressurised fluidised bed gasification with a steam-oxygen mixture as gasifying agent $\left(\mathrm{CFB}-\mathrm{O}_{2}\right)$ are considered in the optimisation. Although not modelled explicitely, the performance of indirectly heated Milena gasification technology developed at ECN [17] can be assimilated to FICFB gasification with an increased cold gas efficiency $\varepsilon_{c g}$ of roughly $3 \%$ since hot and dirty instead of cold and clean producer gas is used as fuel to balance the gasifier's heat demand. This value has been determined in [29] and complies approximately with the efficiency difference reported in Table 1 (cases $\left[17,{ }^{(a)}\right],\left[5,{ }^{(a)}\right]$ ). The prospects of operating an indirectly heated gasifier under pressure are explored in additional runs, although this concept has not been demonstrated in practice. By expanding the combustion gases, such a pressurised system would represent a gasifier that shares its combustion chamber with a gas turbine. Yet technically very challenging, this would allow for generating additional power and thus increase the cogeneration efficiency.

\subsubsection{Gas cleaning}

In each configuration, cold gas cleaning including biodiesel scrubbing is used as the reference technology. In case of gasification and methanation at the same superatmospheric pressure, the benefit obtained through advanced hot gas cleaning is further assessed. For gasification at atmospheric pressure or $\mathrm{CO}_{2}-$ removal upstream of methanation, no benefit is expected from this technology since the producer gas needs to be cooled anyway for compression or separation. 
Table 4: Principal fixed operating conditions and decision variables for optimisation. More detail on constants and assumptions can be found in the process model [5].

\begin{tabular}{|c|c|c|c|c|}
\hline \multirow{2}{*}{$\frac{\text { Technology }}{\text { Drying }}$} & \multicolumn{2}{|l|}{ Operating conditions } & \multirow[t]{2}{*}{ Unit } & \multirow[t]{2}{*}{ Value/Range } \\
\hline & & & & \\
\hline Air drying & Air inlet temperature & $T_{d, i n}$ & ${ }^{\circ} \mathrm{C}$ & {$[180 ; 240]$} \\
\hline \multirow[t]{2}{*}{ Steam drying } & Steam inlet temperature & $T_{d, i n}$ & ${ }^{\circ} \mathrm{C}$ & {$[180 ; 240]$} \\
\hline & Pressure & $p_{d}$ & bar & {$[1 ; 5]$} \\
\hline - both & Moisture content after drying & $\Phi_{d, b m}$ & $\%_{w t}$ & {$[10 ; 30]$} \\
\hline \multicolumn{5}{|c|}{ Thermochemical pretreatment } \\
\hline \multirow[t]{2}{*}{ Torrefaction } & Inlet temperature & $T_{t, i n}$ & ${ }^{\circ} \mathrm{C}$ & {$[300 ; 400]$} \\
\hline & Outlet temperature & $T_{t, \text { out }}$ & ${ }^{\circ} \mathrm{C}$ & 260 \\
\hline \multicolumn{5}{|l|}{ Gasification } \\
\hline \multirow[t]{2}{*}{ Ind. heated FICFB } & Temperature & $T_{g}$ & ${ }^{\circ} \mathrm{C}$ & 850 \\
\hline & Pressure & $p_{g}$ & bar & $1 / p_{m}{ }^{\mathrm{a}}$ \\
\hline \multirow[t]{2}{*}{ Dir. heated CFB } & Temperature & $T_{g}$ & ${ }^{\circ} \mathrm{C}$ & 800 \\
\hline & Pressure & $p_{g}$ & bar & $p_{m}$ \\
\hline \multirow[t]{2}{*}{ - both } & Steam to dry biomass ratio & $r_{S / B}$ & - & 0.5 \\
\hline & \multicolumn{4}{|c|}{ Methane synthesis } \\
\hline \multirow[t]{3}{*}{ Internally cooled FB } & Inlet temperature & $T_{m, i n}$ & ${ }^{\circ} \mathrm{C}$ & {$[300 ; 400]$} \\
\hline & Outlet temperature & $T_{m, \text { out }}$ & ${ }^{\circ} \mathrm{C}$ & {$[300 ; 400]$} \\
\hline & Pressure & $p_{m}$ & bar & {$[1 ; 30]$} \\
\hline \multicolumn{5}{|l|}{ Gas separation } \\
\hline \multirow{3}{*}{$\begin{array}{l}\text { PSA \& Phys. } \\
\text { absorption }\end{array}$} & Wobbe Index ${ }^{b}$ & $W_{s, n}$ & $\mathrm{kWh} \mathrm{Nm}^{-3}$ & {$[13.0 ; 13.5]$} \\
\hline & Amount $\mathrm{CO}_{2}$ removed ${ }^{\mathrm{c}}$ & $r_{\mathrm{CO} 2, \mathrm{rem}}$ & $\%$ & {$[95 ; 99]$} \\
\hline & Methane recovery & $r_{\mathrm{CH} 4}$ & $\%$ & {$[95 ; 99]$} \\
\hline PSA & Adsorption pressure & $p_{P S A}$ & bar & 5.5 \\
\hline \multirow[t]{2}{*}{ Phys. absorption } & Column pressure & $p_{\text {sel }}$ & bar & {$[30 ; 50]$} \\
\hline & Absorption factor & $A_{\text {sel }}$ & - & {$[1 ; 1.8]$} \\
\hline \multirow[t]{7}{*}{ Membranes } & Wobbe Index & $W_{s, n}$ & $\mathrm{kWh} \mathrm{Nm}^{-3}$ & {$[13.0 ; 13.8]$} \\
\hline & Stage cut of stage 1 & $\theta_{1}$ & - & {$[0.2 ; 0.6]$} \\
\hline & Stage cut of stage 2 & $\theta_{2}$ & - & {$[0.2 ; 0.6]$} \\
\hline & Feed pressure of stage 1 & $p_{f 1}$ & bar & {$[5 ; 50]$} \\
\hline & Feed pressure of stage 2 & $p_{f 2}$ & bar & {$[5 ; 50]$} \\
\hline & Feed pressure of stage 3 & $p_{f 3}$ & bar & {$[5 ; 50]$} \\
\hline & Fraction of feed to stage 2 & $s_{i n, 2}$ & - & {$[0 ; 1]$} \\
\hline \multicolumn{5}{|l|}{ Steam network } \\
\hline \multirow[t]{2}{*}{ Production header } & Production pressure & $p_{s, p}$ & bar & {$[40 ; 120]$} \\
\hline & Superheat temperature & $T_{s, s}$ & ${ }^{\circ} \mathrm{C}$ & {$[350 ; 550]$} \\
\hline \multirow[t]{3}{*}{ Utilisation headers } & Number of utilisation levels & $N_{s, u}$ & - & {$[1 ; 4]$} \\
\hline & Temperature of utilisation level $3^{\mathrm{d}}$ & $T_{s, u 3}$ & ${ }^{\circ} \mathrm{C}$ & {$[50 ; 250]$} \\
\hline & Condensation level temperature ${ }^{\mathrm{e}}$ & $T_{s, c}$ & ${ }^{\circ} \mathrm{C}$ & {$[20 ; 110]$} \\
\hline
\end{tabular}

\footnotetext{
${ }^{a}$ pressurised operation only in advanced configurations.

b $\mathrm{CO}_{2}$-removal after methanation.

${ }^{c} \mathrm{CO}_{2}$-removal before methanation.

d levels 1 and 2 are adjusted to steam requirements for gasification and methanation.

e corresponds also to lowest utilisation level.
}

\subsubsection{Methane synthesis}

Methane synthesis is considered to be carried out in an internally cooled fluidised bed that has recently been successfully demonstrated at pilot scale $[12,13]$. Although a thermodynamic model for the fixed bed methanation layout proposed by Haldor Topsøe A/S [53] has been developed, it has not beed considered in the optimisation since the required data for rating and costing of the reactors has not been available. Since equilibrium is reached in both fluid and fixed bed reactors, the conversion efficiency to SNG is yet expected to be the same, and only the combined heat and power production might differ due 


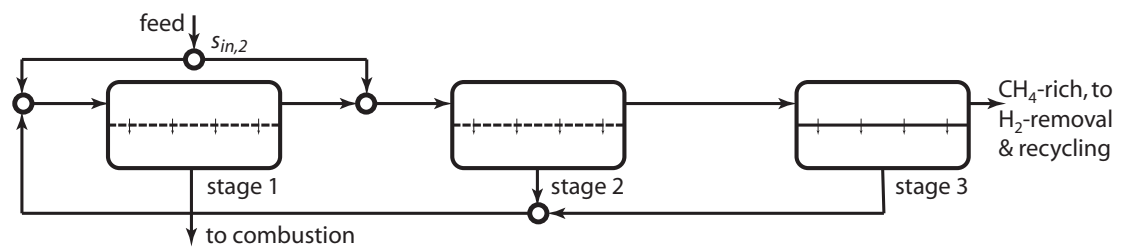

Figure 3: Membrane cascade for $\mathrm{CO}_{2}$ separation (recycle compressors and heat exchangers omitted).

to the dissimilar heat transfer profiles of the reactor heat exchangers [54].

\subsubsection{Gas separation and energy recovery}

In order to find the best technology matches, all possible combinations of the crude SNG production and its conditioning are considered in the optimisation. Pressure swing adsorption (PSA) and physical absorption with Selexol are suitable for $\mathrm{CO}_{2}$-removal both up- or downstream of methanation, whereas membranes can only be applied downstream due to the fast permeation of hydrogen. For this case, three cellulose acetate membrane stages arranged as shown in Figure 3 have been identified as the best subsystem configuration [10]. Downstream to all these $\mathrm{CO}_{2}$-removal options, a final polysulfone membrane for hydrogen removal and recycling to the methane synthesis reactor has further proven useful to reach the required grid quality of $96 \%$ mol $\mathrm{CH}_{4}$. All other depleted gas streams from the liquid-vapour and gas separation units are preheated to $400^{\circ} \mathrm{C}$ and (possibly catalytically) combusted for heat supply or at least harmless release. If necessary, cold producer gas is withdrawn as supplementary fuel to balance the energy requirement of the indirectly heated gasifier. Compared to the other candidate fuels discussed in [29], this is the less performing, yet currently implemented solution due to its technical convenience. In all runs, excess heat is recovered in a steam Rankine cycle whose headers layout and operating conditions are optimised according to Table 4.

\subsection{Objectives}

As discussed in the process design methodology [27], the thermodynamic, economic and environmental indicators defined to measure the process performance are weighted combinations of all material, energy and monetary input and output streams. On this basis, it is argued that the use of all independent flows ${ }^{4}$ as objectives is the most consequent choice for a polygeneration system, since it allows for generating an universal set of optimal configurations that is independent on weighting factors. Although useful for a detailed system design $[10,28,55,56]$ and feasible in principle, this approach is yet cumbersome to comprehensibly compare all potential process configurations of a large superstructure as the one for SNG-production developed in Figure 1. Instead, a more conventional thermo-economic optimisation approach with only one thermodynamic and one economic objective is more appropriate for this purpose.

In many of the previous multi-objective thermo-economic optimisations, exergy efficiency has been chosen as thermodynamic objective since it provides a physically strict appreciation of heat and power in cogeneration applications [40-42,47]. Although no physical argument objects its use in the trigeneration of fuel, heat and power, our analysis has shown that it disproportionately favours the fuel output from a technical point of view [37]. For a balanced weighting of technical relevance, the chemical efficiency $\varepsilon_{\text {chem }}$ based on a SNG-equivalent for heat and power defined in Equation (6) is therefore chosen as thermodynamic objective. As economic objective, the specific investment cost $c_{G R}$ of Equation (7) proves adequate. Unlike the minimisation of the total production costs or the net present value $[40,41,46,48]$, minimising $c_{G R}$ uncouples the thermodynamic performance from the economic objective and complies with the underlying intention of dissociating objectives of different kinds. More importantly, this approach provides the complete range of optimal plant configurations by extending the Pareto front at the

\footnotetext{
${ }^{4}$ i.e. all products and the initial investment costs
} 
low-cost extreme, which is otherwise limited to the economic optimum at fixed economic conditions and process scale.

The choice of $\varepsilon_{\text {chem }}$ and $c_{G R}$ thus balances the need for a comprehensible analysis with the aim of generating an universal set of optimal process configurations that is as independent as possible from the economic parameters, which makes it possible to consider the Pareto-sets as a process configuration database $[57,58]$. For this purpose, the generated data and the functions that are required to access and modify it are available in the electronic supplementary information in Matlab/Octave-language format.

\section{Thermo-economic performance of the candidate technology}

The Pareto-optimal sets of all process configurations presented in Figure 4(a) provide a general overview of the optimal thermo-economic performances at a scale of $20 \mathrm{MW}_{t h, b m}$. Figures on the left present the results where the excess heat is converted into electricity, while figures on the right also allow for heat cogeneration to maximise the combined heat and power production with respect to $\varepsilon_{\text {chem }}$. The latter correspond to situations where the plant is either integrated into an industrial cluster or a district heating system. As demonstrated in the analysis, it is important to note that the optimal technology choice, operating conditions and performance of the Pareto-optimal configurations differs if heat cogeneration is considered or not.

Without industrial heat cogeneration, most of the configurations based on indirectly heated FICFB gasification at atmospheric pressure reach chemical (i.e. SNG-equivalent) efficiencies between 60 and $76 \%$ for specific investment costs ranging from 1000 to $1300 \$ \mathrm{~kW}^{-1}$. Directly heated, pressurised oxygen-blown gasification reaches higher efficiencies of 68 to $80 \%$ with lower investment costs of 700 to $1000 \$ \mathrm{~kW}^{-1}$ and clearly dominate the ones of its competitor. Industrial heat cogeneration allows for slightly decreasing the investment costs and increasing the chemical efficiency up to $80 \%$ and $86 \%$ for indirectly and directly heated technology, respectively. If indirectly heated gasification could be operated under pressure, the gap between the two technologies narrows. A combined gasification/gas turbine configuration could reach over $80 \%$ chemical efficiency without heat cogeneration and thus even outperform $\mathrm{CFB}-\mathrm{O}_{2}$ gasification at the high-efficiency end.

Table 5 summarises the maximum efficiencies that can be obtained for the polygeneration of SNG, electricity and heat. While the SNG yield with FICFB gasification is limited to $69-71 \%, 75-77 \%$ can be reached with $\mathrm{CFB}-\mathrm{O}_{2}$. If no steam cycle is used, the electricity balance is clearly negative, but up to $20 \%$ of heat at $110^{\circ} \mathrm{C}$ can be cogenerated to attain a total energy efficiency of 85 to $90 \%$. Converting the excess heat in a steam Rankine cycle allows to recover 5-8\% of the raw material's heating value as electrical power, and covers significantly more than the plant's own consumption. The combined production of heat and power from excess heat allows for maximum chemical and exergy efficiencies of $80-86 \%$ and $67-73 \%$, respectively. Figures 4 (b)-(c) illustrate the variation of the product yields trough a linear regression of the partial efficiencies $\varepsilon_{i}$ defined in Equations (1)-(3) on the the chemical efficiency $\varepsilon_{c h e m}$ (Eq. 6). For each process configuration, (b) shows the mean values of $\varepsilon_{S N G}, \varepsilon_{e l}$ and $\varepsilon_{t h}$ on a Pareto front and (c) the slope of the correlation on $\varepsilon_{\text {chem }}$. In most of the cases, $\Delta \varepsilon_{S N G} / \Delta \varepsilon_{\text {chem }}$ is close to zero, which highlights that the amount of SNG produced by a specific technology combination is constant in these Pareto set. The operating conditions of the thermochemical conversion are thus not conflicting with respect to investment cost and SNG yield, and the trade-off between efficiency and cost within a specific process configuration is mainly related to the cogeneration of heat and power.

In the following sections, the thermo-economic performance of the candidate technologies and the influence of the operating conditions are discussed in detail. A summary of the major findings in terms of technology selection, cost, process integration and its effects on the polygeneration is provided in Table 6. 

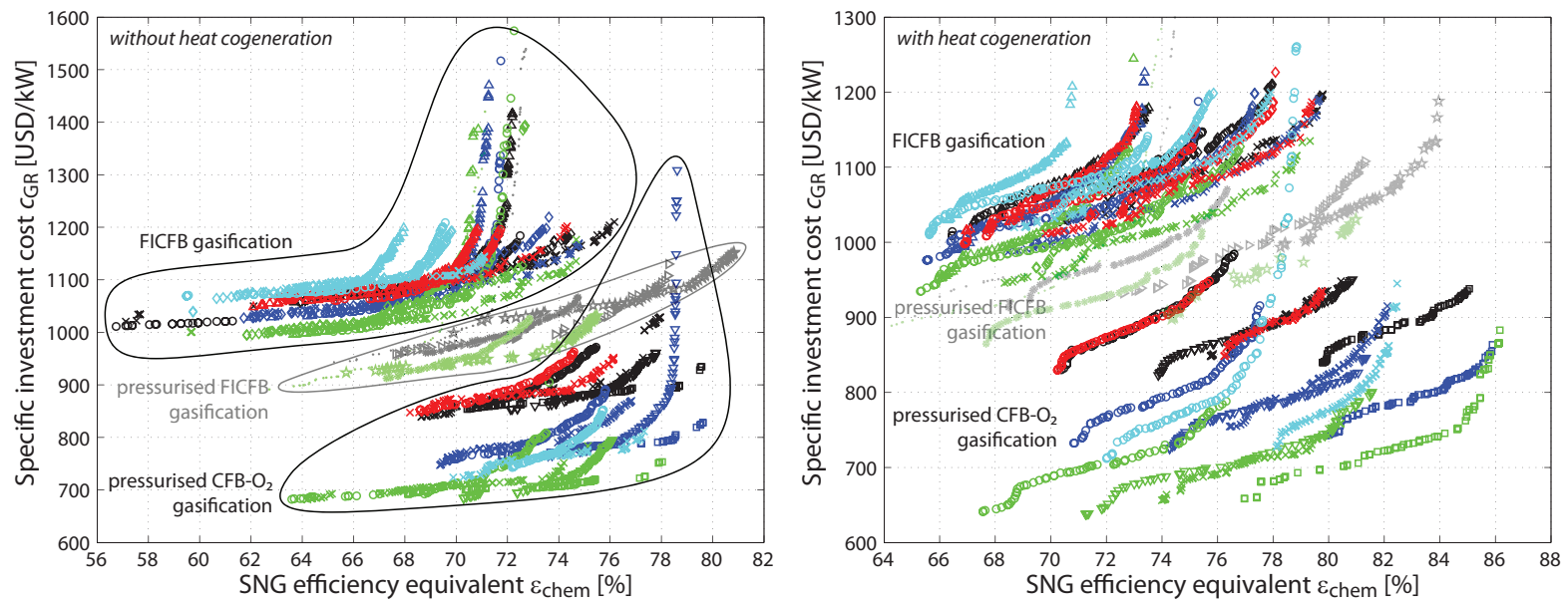

(a) - Pareto-optimal solutions of all examined process configurations.
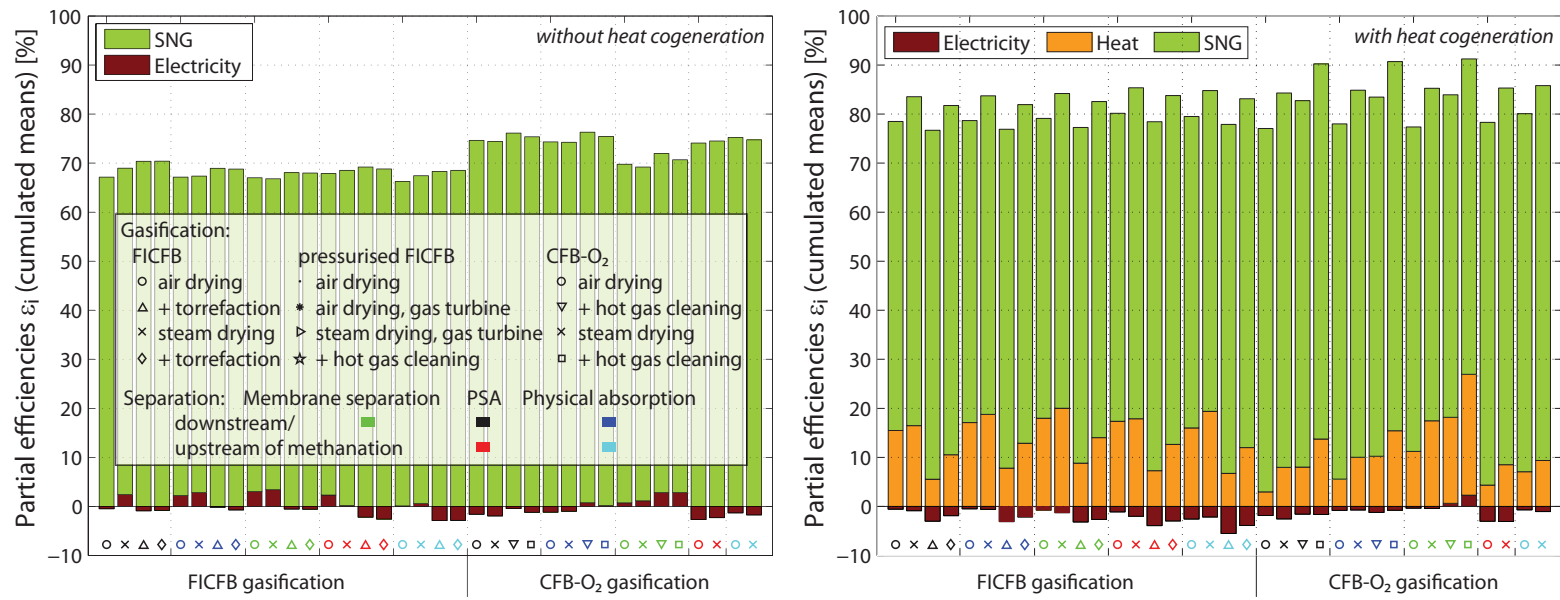

(b) - Regressed product distribution on a Pareto front: Mean values of $\varepsilon_{S N G}, \varepsilon_{e l}$ and $\varepsilon_{t h}$.
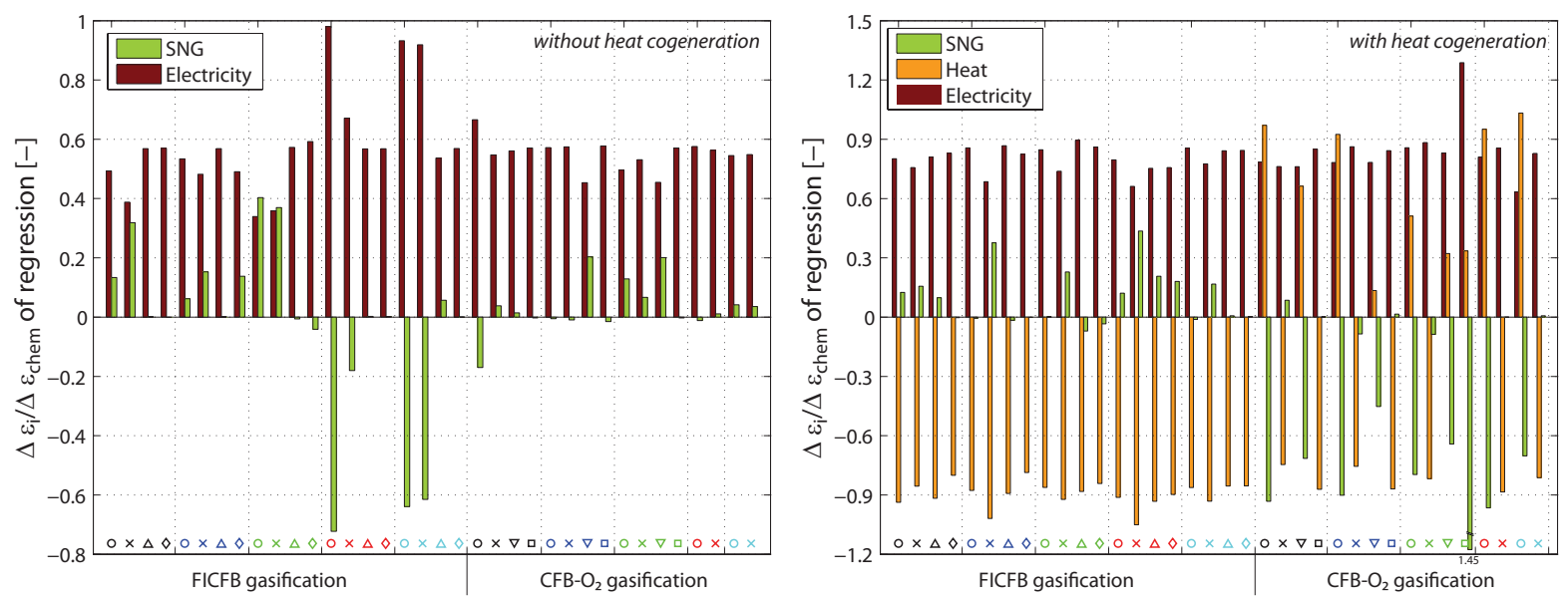

(c) - Regressed product distribution on a Pareto front: Slopes of the regression.

Figure 4: Thermo-economic characteristics of all examined process configurations without (left) and with heat cogeneration.

\subsection{Drying}

\subsubsection{Performance of air and steam drying}

Figure 5(a) compares the representative performance curves of the pretreatment options for FICFB gasification with PSA and membrane separation technology. If industrial heat cogeneration is not considered, 
Table 5: Efficiencies of best polygeneration flowsheets with respect to $\varepsilon_{\text {chem }}$.

\begin{tabular}{lllrrrrrr}
\hline System $^{\mathrm{a}}$ & & & $\varepsilon_{S N G}$ & $\varepsilon_{\text {el }}$ & $\varepsilon_{\text {th }}$ & $\varepsilon_{\text {chem }}$ & $\varepsilon$ & $\eta$ \\
\hline FICFB & $\mathrm{F}$ & $\times$ & 69.0 & -4.0 & - & 62.1 & 65.1 & 61.5 \\
& $\mathrm{~F}^{\mathrm{b}}$ & $\diamond$ & 71.4 & -6.6 & - & 59.7 & 64.7 & 62.1 \\
& $\mathrm{FH}$ & $\times$ & 69.4 & -4.4 & 20.4 & 73.2 & 85.4 & 64.6 \\
& $\mathrm{FP}$ & $\times$ & 69.1 & 4.1 & - & 76.2 & 73.1 & 67.2 \\
& FHP & $\times$ & 69.3 & 1.9 & 12.5 & 79.8 & 83.7 & 67.5 \\
\hline $\mathrm{CFB}^{-\mathrm{O}_{2}}$ & $\mathrm{~F}$ & $\times$ & 76.8 & -3.2 & - & 71.2 & 73.6 & 68.7 \\
& FH & $\square$ & 75.4 & -3.2 & 18.6 & 80.4 & 90.8 & 70.4 \\
& FP & $\square$ & 75.1 & 2.6 & - & 79.6 & 77.7 & 71.4 \\
& FHP & $\square$ & 43.4 & 12.0 & 38.2 & 86.2 & 93.5 & 57.4 \\
& FHP & $\square$ & 75.3 & 1.6 & 13.8 & 85.9 & 90.7 & 72.9 \\
\hline
\end{tabular}

a (Poly)generation of F: fuel, H: heat, P: power. See Figure 4 for marker legend.

b best configuration with respect to $\varepsilon_{S N G}$, but reduced $\varepsilon_{\text {chem }}$ due to $\varepsilon_{e l}$.

c $2^{\text {nd }}$ best configuration with respect to $\varepsilon_{c h e m}$ with high $\varepsilon_{S N G}$.

air drying is the better drying technology at the low-efficiency end. Above a chemical efficiency of approximately $67 \%$ (PSA) to $69 \%$ (membrane separation), the Pareto fronts of the drying technologies intersect and steam drying gets clearly dominating. The same conclusion can be drawn for the other configurations and is due to the recovery of the latent heat of the moisture as useful process heat. When excess heat can be valorised in a district heating system, steam drying is clearly the best technology in the entire Pareto domain (Fig. 5(a), right), which is characterised by a constant translation from air to steam towards considerably higher efficiencies at slightly higher costs.

\subsubsection{Drying temperature}

The optimal drying temperatures depend on the technology and can be explained with the individual equipment performance. As shown earlier [5], the heat demand for air drying is markedly decreasing with the air inlet temperature $T_{d, i n}$, which is beneficial for the overall process since more excess heat is available for CHP. In the optimisation, $T_{d, i n}$ of air is not conflicting and always at its higher bound $\left(240^{\circ} \mathrm{C}\right)$ defined in Table 4 . If steam drying is used, the heat requirement and the specific power consumption for drying are slightly decreasing with temperature [5]. The inlet temperature $T_{d, \text { in }}$ of the steam is thus conflicting with respect to the thermo-economic performance of the entire process, which is more efficient at its lower bound $\left(180^{\circ} \mathrm{C}\right)$ and less costly at its higher bound $\left(240^{\circ} \mathrm{C}\right)$. In all configurations with steam drying, the operating pressure is preferably chosen at the upper limit (5 bar). A compact process setup might consist in operating the steam dryer as a steam generator for methane synthesis.

\subsubsection{Residual moisture content}

Independently on technology, the residual moisture content $\Phi_{d, b m}$ of the dried biomass is a key variable in the process design. Limiting the moisture content in the gasifier feed allows for decreasing its energy requirement at high temperature and the exergy losses during gasification [29]. This affects the cold gas efficiency $\varepsilon_{c g}$ by about $10 \%$ as observed for FICFB technology, which is yet partially compensated with respect to overall performance by CHP from the increased heat excess below the pinch. The moisture content is conflicting with respect to the conversion efficiencies $\varepsilon_{S N G}, \varepsilon_{e l}$ and $\varepsilon_{t h}$ and thus within the thermodynamic objective $\varepsilon_{c h e m}$ itself. For most of the configurations, a value of $\Phi_{d, b m}$ at the considered lower bound of $10 \%$ is beneficial for high chemical efficiency but also requires higher investments. However, for air drying with heat cogeneration or air drying coupled with torrefaction, decreasing $\Phi_{d, b m}$ at the expense of a higher dryer heat load does not pay off, the variable is not conflicting and always at its upper bound of $30 \%_{w t}$. 
Table 6: Major findings of the system analysis[5, 10, 29] and the present thermo-economic optimisation of SNG production from biomass.

\begin{tabular}{l} 
Process integration \& polygeneration \\
\hline Pretreatment \\
- drying with steam is advantageous due to the recovery of latent heat from \\
evaporated moisture at useful temperature \\
- drying level $\Phi_{d, b m}$ at the gasifier inlet \\
- determines exergy loss in gasifier due to heat transfer across pinch [29] \\
$\rightarrow$ with $\Phi_{d, b m} \uparrow: \varepsilon_{c g} \& \varepsilon_{S N G} \uparrow, \varepsilon_{e l} \& \varepsilon_{t h} \downarrow$ since less heat available for \\
CHP \\
- overall, low values ( $<15 \%$ residual humidity) are preferable \\
thermochemical pretreatment (pyrolysis, torrefaction) decreases the heat re- \\
quirement in gasifier due to partial decomposition with heat below pinch: \\
$\varepsilon_{S N G} \uparrow$, but $\varepsilon_{e l} \& \varepsilon_{t h} \downarrow$ since less excess heat is available \\
- torrefaction is not efficient with respect to weighting applied by $\varepsilon_{c h e m}$ \\
since penalty on $\varepsilon_{e l}$ and $\varepsilon_{t h}$ is too high \\
$\rightarrow$ torrefaction should only be applied if the waste heat is not valorised by \\
CHP
\end{tabular}

\section{Gasification}

- fluidised bed gasification (both directly and indirectly heated) emerges as best technology due to moderate temperatures $\left(800-850^{\circ} \mathrm{C}\right)$ and relatively large distance to equilibrium [5, 29]:

- high $\mathrm{CH}_{4}$ yield

- process is less endothermal at $T_{g}$ and less exothermal at $T_{m}$ compared to high $\mathrm{H}_{2}$ (\& $\left.\mathrm{CO}\right)$-yield at equilibrium

- gasification requires less heat $\left(\varepsilon_{S N G} \uparrow\right)$ and less excess heat is available $\left(\varepsilon_{e l} \& \varepsilon_{t h} \downarrow\right)$

- pressurised gasification makes intermediate compression of voluminous producer gas obsolete

- indirectly heated gasification:

- rather low $\varepsilon_{c g}$ due to pinch at high temperature, and the need to heat the $\mathrm{N}_{2}$ of the combustion air up to this temperature (which is not the case in $\mathrm{O}_{2} / \mathrm{H}_{2} \mathrm{O}$-gasification)

- use of off-gases and integrated design with the gas separation system is beneficial [10]

- although technically very challenging, operation under pressure in a combined gas-turbine configuration would considerably increase the efficiency

- directly heated $\left(\mathrm{O}_{2} / \mathrm{H}_{2} \mathrm{O}\right)$ gasification:

- efficient: heat load is low since no bulk- $\mathrm{N}_{2}$ is present

\section{Gas cleaning}

- hot cleaning (without condensation) is only beneficial if gasifier \& methanation are close-coupled (i.e. for pressurised gasification and $\mathrm{CO}_{2}$-removal after methanation): $\varepsilon_{\text {chem }}$ increases by $3-5 \%$

\section{Methane synthesis}

- internally cooled fluidised bed gasification: excess heat is accessible at higher temperature than in intercooled fixed beds [54] Technology \& Cost

- air drying is cheaper, but less efficient than steam drying
- indirectly heated gasification:

- bulky, complex \& expensive twin-reactor

- directly heated $\left(\mathrm{O}_{2} / \mathrm{H}_{2} \mathrm{O}\right)$ gasification:

- $\mathrm{O}_{2}$ requirement is not significantly penalising

- moderately pressurised gasification

- compact and less expensive vessels

- lock-hopper feeding system is not excessively penalising the cost

- producer gas compressor is obsolete

- better economy of scale due to increased capacity per unit (cf. Tab. 7 and [5])
- beneficial size and cost reduction of downstream gas cleaning in case of pressurised gasification
$\mathrm{CO}_{2}$-removal: There are several competing technologies with distinct advantages:

- low gas recovery is not a penalty if depleted gas can be used (e.g. indirectly the size) [10]

- membranes typically reach lower $\mathrm{CH}_{4}$-recoveries than PSA and physical absorption, they are thus especially suitable if the value of the depleted gas can be recovered (ind. heated gasification \& district heating)

\footnotetext{
$\bullet$
} heated gasification) - optimal separation system may become smaller (half methanation and grid

- scaling (cf. Tab. 7):

- membranes are rel. cheap, but suffer from limited economy of scale

- PSA: matches well with gas. at atm. pressure

- phys. abs.: matches well with press. gas. and largescale

- $\mathrm{CO}_{2}$ can be recovered relatively cheap [10]

\section{Energy recovery \& cogeneration}

- contributes significantly to energy- and cost-efficient process design (cf. Table 5): 5-10\% of biomass input can be recovered as electrical power (or up to $20 \%$ as heat)
作 15 bar), at higher pressure costs increase

- pressure must match with gasification, separation and grid - the optimal value is thus interdependent with technology choice and scale 

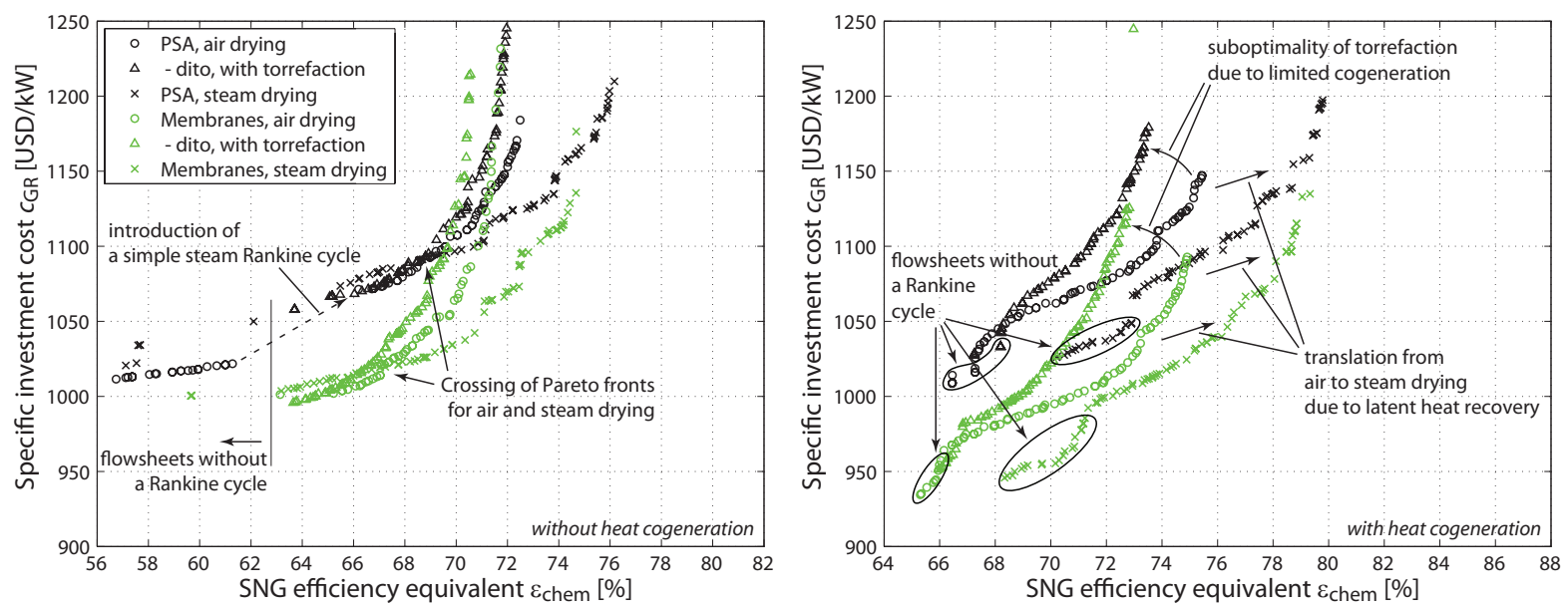

(a) - Pretreatment options for FICFB-gasification.
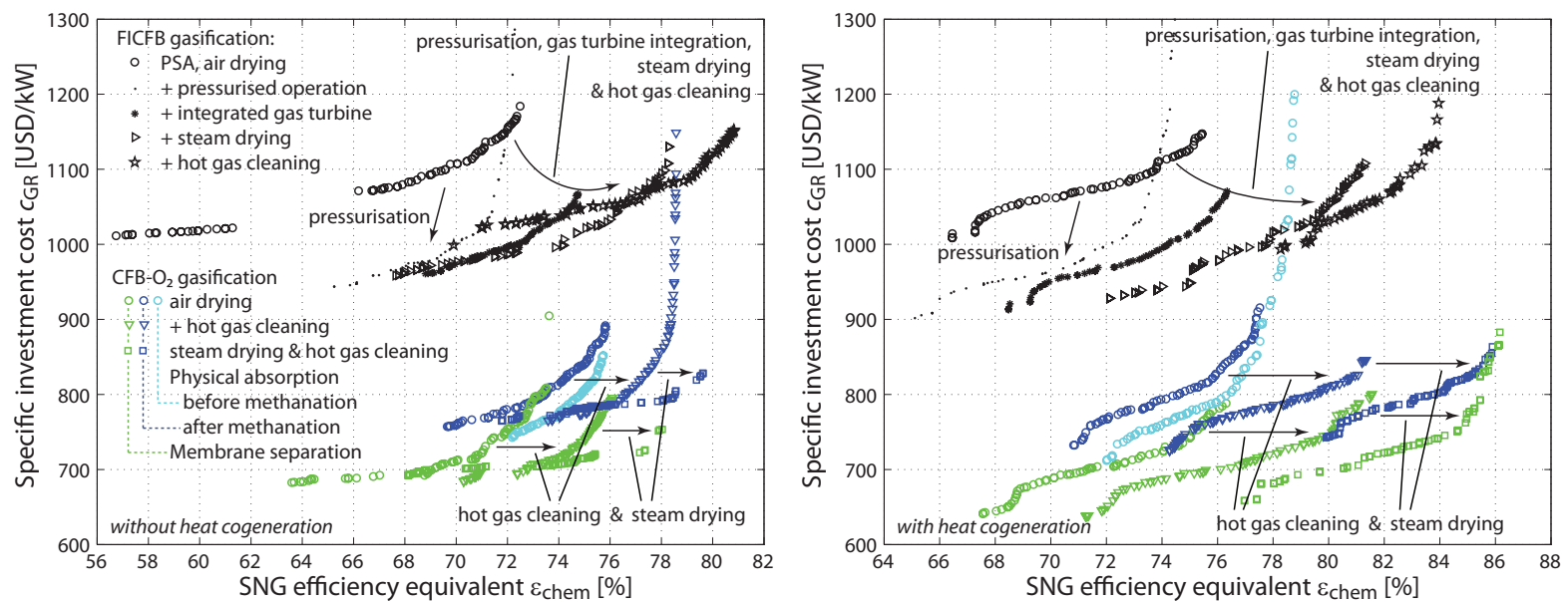

(b) - Advanced technologies (hot gas cleaning and pressurised FICFB).
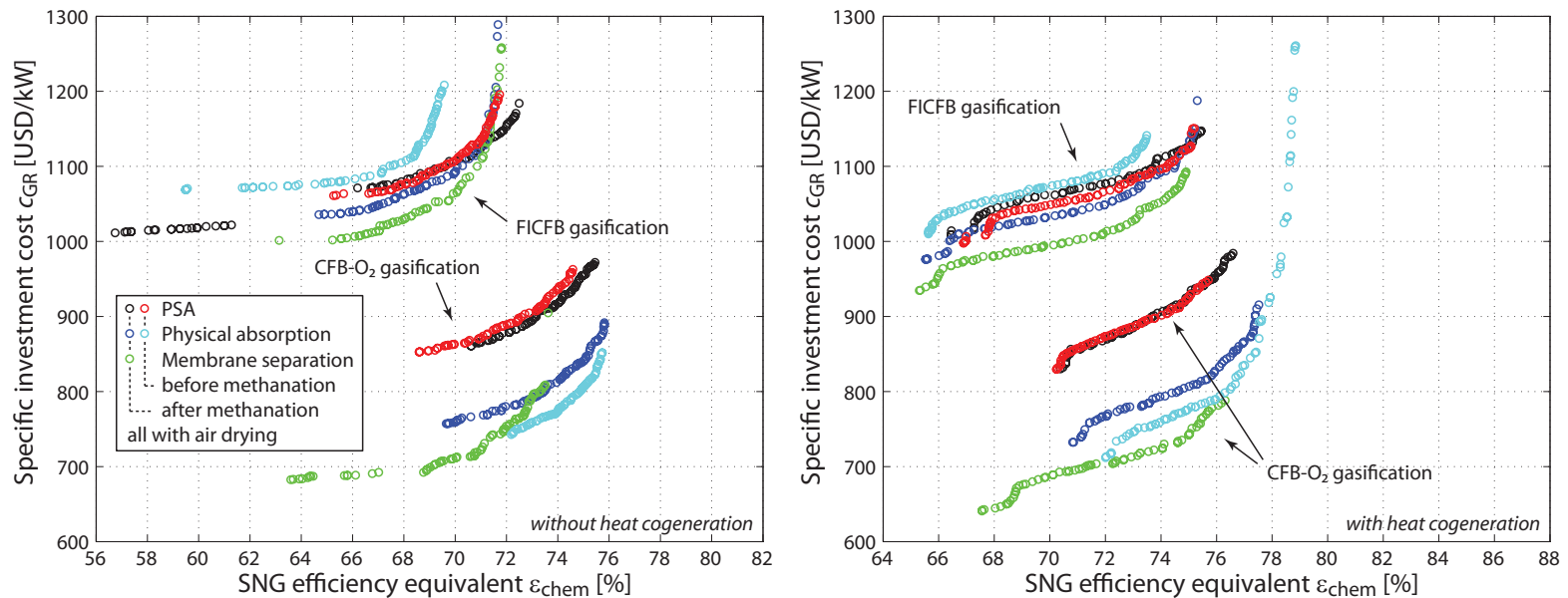

(c) - $\mathrm{CO}_{2}$-removal options for both gasification technologies in case of air drying.

Figure 5: Pareto-optimal solutions for selected configurations without (left) and with heat cogeneration.

\subsection{Thermochemical pretreatment by torrefaction}

The energy integration effects of drying are further intensified when the gasifier feed is completely dried and partly decomposed in a thermochemical pretreatment like torrefaction. Compared to configurations without torrefaction, this optional process step increases the SNG yield to the expense of less cogenerated 
heat. However, the weighting applied in the calculation of $\varepsilon_{\text {chem }}$ does not balance the reduced contribution of the by-products with the increased fuel output, and the Pareto fronts of the configurations with torrefaction on Figure 5(a) are outperformed at elevated chemical efficiency. In all cases, the torrefaction inlet temperature $T_{t, \text { in }}$ converges to its upper bound of $400^{\circ} \mathrm{C}$.

\subsection{Gasification}

As already discussed in the introductory section, the general performance overview of Figure 4(a) highlights the distinctive character of the gasification technology with respect to the process performance. With 35 to $45 \%$ higher investment costs and 4 to 6\%-points lower chemical efficiency, indirectly heated FICFB gasification at atmospheric pressure is clearly suboptimal compared to directly heated steamoxygen gasification under pressure. On the one hand, the indirect heat supply at atmospheric pressure requires a complex twin-reactor, bulky gas cleaning and intermediate compression, which is more expensive than a compact process design with a directly heated pressurised vessel. On the other hand, efficiency is limited by the relatively low cold gas efficiency due to the high pinch temperature and the power required for intermediate gas compression [5]. As argued in Paragraph 3.2.2, the use of hot producer gas in ECN's indirectly heated Milena gasification [17] can partly compensate the gap in efficiency due to a cold gas efficiency that is roughly 3\% higher than for FICFB technology [29]. Since the gas composition of both directly and indirectly heated fluidised bed gasification have been found equidistant to the thermodynamic equilibrium [5], the loss of chemical energy as heat in the exothermal methanation of their producer gas is similar. For this reason, the overall SNG yield $\varepsilon_{S N G}$ for a system based on Milena gasification can also be assumed to be roughly 3\%-points higher than the results for FICFB gasification presented here.

Although technically challenging, a pressurisation of the FICFB gasification reactor could partially compensate its disadvantages with respect to performance. As illustrated in Figure 5(b), increasing the vessel pressure to the level of methanation decreases the system cost by roughly $10 \%$. If the power requirement for air compression is not recovered, efficiency yet drops as well. This negative effect is avoided if the hot combustion gases could be expanded in a turbine, which increases the chemical efficiency by up to $8 \%$-points.

\subsection{Gas cleaning}

In addition to the immediate benefit on the process performance, pressurised gasification is the basis for the use of advanced hot gas cleaning technology since intermediate gas cooling, vapour condensation and compression is made redundant. Figure 5(b) shows that closely coupling the gasification and methanation reactors through hot cleaning increases $\varepsilon_{\text {chem }}$ by up to 3 and $5 \%$ for the setups without and with heat cogeneration, respectively.

Combined with steam drying and directly heated pressurised gasification, hot gas cleaning thus constitutes the globally optimal process configurations. With an increased SNG yield due to the use of hot gas for balancing the heat requirement, pressurised FICFB gasification might further complement the set of globally optimal configurations at the top efficiency end of Figure 4(a).

\subsection{Methane synthesis}

\subsubsection{Reactor temperatures}

In all candidate configurations, methanation in an internally cooled fluidised bed is considered as the reference technology with a linear temperature-enthalpy profile between the inlet and outlet of the reactor. Except for upstream $\mathrm{CO}_{2}$-removal, these temperatures converge to their upper $\left(400^{\circ} \mathrm{C}\right)$ and lower $\left(300^{\circ} \mathrm{C}\right)$ bounds, respectively, which allows for an efficient heat recovery in the steam network while limiting the residual $\mathrm{H}_{2}$ and $\mathrm{CO}$ concentration. If $\mathrm{CO}_{2}$ is removed before methanation, cheaper configurations are obtained for lower gas temperatures at the reactor inlet. 


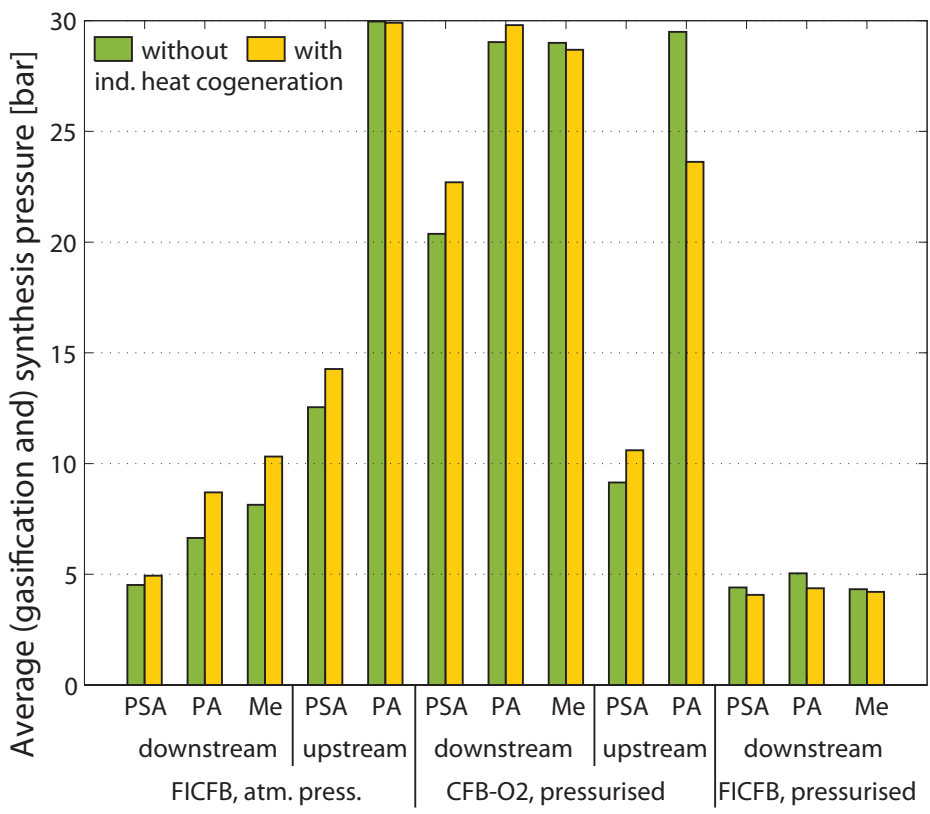

Figure 6: Averages of optimal synthesis pressures for different gasification technologies with gas separation downor upstream of methanation (PSA: Pressure swing adsorption, PA: Physical absorption, Me: Membranes).

\subsubsection{Synthesis pressure}

As indicated by the mean value of the synthesis pressure for the different process configurations shown in Figure 6, the optimal methanation pressure $p_{m}$ depends both on the gasification and gas separation technology. For a given configuration, this pressure is slightly conflicting. While efficiency is typically negatively correlated with pressure due to compression power requirements, considerable cost savings are obtained with a compact, mildly pressurised reactor. If pressure is further increased, this benefit is outweighed by an increasing cost factor related to the amount of required steel.

In case of FICFB gasification at atmospheric pressure, the methane synthesis is best realised at a mild pressurisation of 3-10 bar. Within this range, slightly higher values are obtained for the physical absorption and membrane separation processes than for PSA. If $\mathrm{CO}_{2}$ is removed prior to synthesis, the operating pressure of the separation and the synthesis should be matched in order to avoid supplementary turbomachinery. In pressurised indirectly heated gasification, the twin reactor dominates the system performance and the optimal pressure depends on the gas separation technology.

In case of directly heated gasification at the synthesis pressure, gas compression requirements are minimised at elevated system pressure and its optimal values are all in the upper half of the search space (i.e. $15-30$ bar).

\subsection{Gas separation}

Figure 5(c) compares the thermo-economic process characteristics of the $\mathrm{CO}_{2}$-removal configurations with air drying and cold gas cleaning, and thereby highlights that the separation system must match with the selected gasification technology.

\subsubsection{Indirectly heated gasification}

For an indirectly heated gasifier, gas separation by membranes dominates a large part of the Pareto domain and gets only suboptimal at the top-efficiency end where PSA becomes the best choice. The performance of physical absorption with Selexol is always worse than membrane technology whose permeate is appropriate for heating the gasification reactor [10]. Furthermore, the pressure levels imposed 
by upstream $\mathrm{CO}_{2}$-removal are not favourable for process configurations based on FICFB technology and result in suboptimal performance.

\subsubsection{Directly heated pressurised gasification}

Since they are both operated at elevated pressure, directly heated gasification matches better with physical absorption than with a PSA system. For cold gas cleaning, an upstream separation column performs better than its downstream alternative, but cannot benefit from hot gas cleaning. Although dominating the low-cost configurations, membrane technology suffers from the fact that the heat of combustion of the depleted permeate can not be valorised in directly heated gasification. The obtained SNG yield is thus lower when compared to the other CFB-O2 configurations, and the increase in heat and power cogeneration from waste heat does not entirely compensate for the decreasing gas efficiency.

\subsubsection{Optimal operating conditions}

For PSA separation systems, the decision variables of Table 4 are not conflicting and the best performance is always obtained at the upper purity- and recovery-limit of the technology. In Selexol absorption, lower purity and intermediate recovery levels than for PSA should be targeted, although no general trends emerge. In any case, the optimal separation pressure sticks to its lower bound of 30 bar in order to limit the compression requirements. The column design is thereby conflicting with respect to the absorption factor, whose optimal value ranges between 1.2 and 1.6 and is positively correlated with both efficiency and investment cost. Cellulose acetate membranes are generally best arranged in a three-stage cascade with a common recycling loop and feeding the crude to the first stage of Figure 3. In order to limit the compression requirement from $p_{m}$ to $p_{\text {grid }}$, a high separation in the first stages and increasing pressure on the retentate side of the subsequent stages is worthwhile. Accordingly, decreasing stage cuts and optimal operating pressure of 35 to 45 bar, 40 to 45 bar and 50 bar for the $1^{\text {st }}, 2^{\text {nd }}$ and $3^{\text {rd }}$ stage, respectively, are obtained.

\subsection{4 $\mathrm{CO}_{2}$-capture in membrane separation}

The elevated share of $\mathrm{CO}_{2}$ in the crude product encourages not only to recover methane as SNG, but also the biogenic $\mathrm{CO}_{2}$ that could be sequestrated and lead to a negative $\mathrm{CO}_{2}$ emission balance over the overall product lifecycle. As detailed in earlier work [10], the addition of an enriching stage for the permeate of membrane 1 on Figure 3 and a catalytic combustion of the residuals with enriched air would allow for capturing up to $30 \%$ of the feedstock's carbon in the form of $\mathrm{CO}_{2}$ at $95 \%$ purity and 1 bar. This can be done with a penalty below $2 \%$ with respect to the process efficiency and costs 15 to $40 \$$ ton $_{\mathrm{CO} 2}^{-1}$ depending on the price of electricity, and is thus more economic than at fossil fuel power plants.

\subsection{Energy recovery}

As introduced in the discussion of Figures 4(b)-(c) and Table 5, energy recovery by a steam Rankine cycle has an essential impact on the thermo-economic plant performance and causes a large part of the variation within the Pareto front of a specific configuration. Although a priori considered in all runs, the optimisation algorithm may prevent the implementation of a Rankine cycle by imposing infeasible conditions, and thus provide some Pareto-optimal solutions without a steam cycle and therefore lower investment cost. These configurations indicate that the chemical process efficiency is limited to $62 \%$ and $71 \%$ for conventional FICFB and pressurised CFB- $\mathrm{O}_{2}$ gasification, respectively, if no energy at all is recovered from excess heat. If at least heat can be valorised, the lack of a steam cycle allows for $73 \%$ and $80 \%$ equivalent efficiency for the same cases. Figure 5(a) thereby highlights that the introduction of a steam cycle generates a jump discontinuity in the Pareto front if only power is cogenerated (left), or an inflection point if the power output rivalises with the one of heat (right). With a gross power generation of up to $10 \%$ of the biomass input, the chemical efficiency is improved by 4 to $14 \%$-points if power is the only by-product. If both power and heat can be valorised, around $35 \%$ of the waste heat can be converted 
to power. This corresponds to a gross power production of 5 to $8 \%$ of the raw material's heating value and improves the chemical process efficiency by up to 7\%-points. Except the steam turbine inlet temperature $T_{s, s}$ that is positively correlated with process efficiency and cost, the operating conditions of the steam cycle do not follow general trends and need to be optimised specifically for each process configuration.

\section{Process scaling}

\subsection{Approach}

As stated in the problem formulation, all thermo-economic process optimisations have been carried out for a reference capacity of $20 \mathrm{MW}_{t h, b m}$. The specific investment cost for the candidate technologies is yet expected to change with scale, which needs to be accounted for if a general comparison is targeted. From the design perspective, this is important since the economic and environmental plant performance is also strongly dependent on the wood supply chain $[31,58]$. Individual process optimisations at multiple scales would thus be necessary in principle, but are cumbersome since they require a large computational effort. For this reason, a simplified approach that is based solely on a single reference scale has been tested and proves valid. Assuming that the operating conditions within a set of Pareto-optimal flowsheets do not substantially change with process scale, the optimal configuration at any other scale could be selected by extrapolating the optimised flowsheets from the reference scale. This does not mean that the best process flowsheet with respect to a particular performance indicator is scale-independent, but that it may be chosen from a scale-independent set of Pareto-optimal solutions. Since the thermodynamic objective is inherently independent on scale, suboptimality may thereby only arise with respect to investment cost. This simplifying hypothesis has been tested for the major process configurations (i.e. FICFB and CFB$\mathrm{O}_{2}$ gasification with air and steam drying, and PSA, Selexol and membrane separation after methanation) with and without heat cogeneration. A comparison at 5 and $100 \mathrm{MW}_{t h, b m}$ of the Pareto fronts obtained by optimisation or by extrapolation from the reference scale has confirmed that the differences are indeed small [37, (App. B) $]$. In more than half of the 24 test cases, the difference in investment cost is within $1-2 \%$, in one third of the cases it is smaller than $5 \%$ and never larger than $7 \%$.

\subsection{Scaling correlations}

In order to provide a measure of the economies of scale to be expected for the process technology, the investment cost $C_{G R}[\$]$ of the Pareto-optimal configurations can be regressed on the plant scale with a conventional scaling law of the form:

$$
C_{G R}=C_{G R, r e f}\left(\frac{\Delta h_{b m}^{0} \dot{m}_{b m}^{+}}{\left(\Delta h_{b m}^{0} \dot{m}_{b m}^{+}\right)_{r e f}}\right)^{b}
$$

or, for the specific investment $\operatorname{cost} c_{G R}\left[\$ \mathrm{~kW}_{b m}^{-1}\right]$ of Eq. (7):

$$
c_{G R}=c_{G R, r e f}\left(\frac{\Delta h_{b m}^{0} \dot{m}_{b m}^{+}}{\left(\Delta h_{b m}^{0} \dot{m}_{b m}^{+}\right)_{r e f}}\right)^{(b-1)}
$$

in which the subscript ref refers to the reference scale and the cost exponent $b$ is smaller unity. For chemical process equipment, $b$ typically ranges from 0.4 to 0.9 and average values between 0.6 and 0.7 are often assumed [33]. However, the size of the process units, and in particular vessels, is limited to manageable dimensions. In our model, we allow for maximum diameters of $4 \mathrm{~m}$ and $3 \mathrm{~m}$ for vertical and horizontal vessels, respectively [5]. Parallel arrangement is therefore required at larger scales, which leads to a linearisation of Equation (14).

Figure 7 compares the scaling characteristics of two exemplary process setups regressed either piecewise in the intervals [5; 20] and [20; 200] MW or over its entire domain [5; 200] MW. For this regression, the calculated investment cost at 5, 10,20,50,100 and $200 \mathrm{MW}$ and a unique cost exponent $b$ for all 


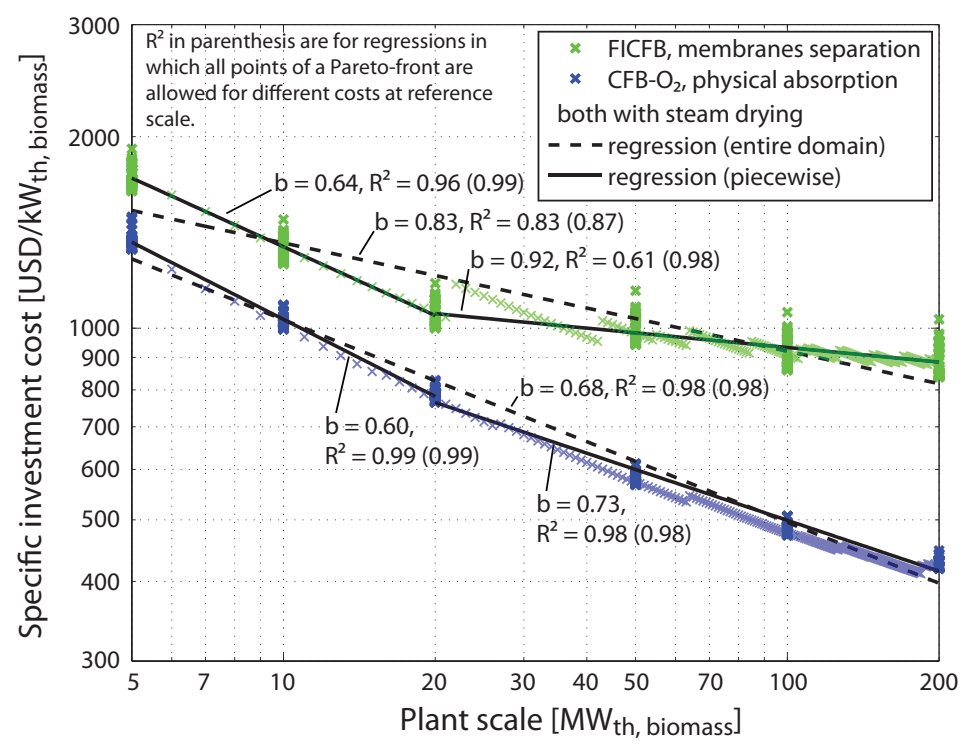

Figure 7: Regression of the exponent $b$ in the cost correlation of Eq. (15) for two exemplary process configurations.

Table 7: Regressed cost exponents for principal process configurations. The coefficient of determination $\mathrm{R}^{2}$ is between 0.97 and 0.99 if individual costs values at reference scale are allowed. The reference value of $c_{G R, r e f}$ in Eq. (15) for a specific configuration is given directly in one of the Figures 4(a)-5(c).

\begin{tabular}{lcccccc}
\hline $\begin{array}{c}\text { Separation } \backslash \text { Gasification } \\
\text { Range }\left[\mathrm{MW}_{t h, b m}\right]\end{array}$ & \multicolumn{2}{c}{ FICFB } & \multicolumn{2}{c}{ CFB-O2 } & \multicolumn{2}{c}{ FICFB (press.) } \\
\hline PSA & 0.63 & 0.90 & 0.64 & 0.78 & 0.64 & 0.80 \\
Physical absorption & 0.60 & 0.89 & 0.58 & 0.73 & 0.58 & 0.76 \\
Membranes & 0.64 & 0.92 & 0.64 & 0.78 & 0.64 & 0.81 \\
\hline
\end{tabular}

configurations on the Pareto-front of each technology scenario are considered. At small plant scales, the lines for FICFB and CFB-O2 gasification are nearly parallel in logarithmic coordinates and economies of scale are significant. Not much above $20 \mathrm{MW}_{t h, b m}$, however, the bulky vessels operated near atmospheric pressure reach their limits and parallel processing in several units is necessary in case of gasification at atmospheric pressure. As a consequence, smaller economies of scale are realised at larger scale and a piecewise regression with a flatter slope above $20 \mathrm{MW}_{t h, b m}$ is appropriate. This effect is much less pronounced in the configurations based on pressurised gasification since their process units can be operated at higher capacity. Furthermore, Section 4.6.2 has shown that pressurised gasification matches better with liquid absorption technology, for which more important economies of scale than with the inherently linearly scaling of PSA or membrane separation can be obtained.

The overall cost exponents for the principal technology groups reported in Table 7 confirm these trends. Similar to Figure 7, they have been obtained by regressing a unique cost exponent for all Paretooptimal configurations. Each process flowsheet is thereby allowed for an individual specific reference cost $c_{G R, r e f}$ at $20 \mathrm{MW}_{t h, b m}$ that can be identified directly from Figures 4-5 or the optimal configurations discussed in the following section and detailed in Table 9.

\section{Optimal configurations with respect to scale}

The last step of the conceptual process design consists in selecting a specific flowsheet from the generated database of thermo-economically optimal process configurations, which is typically based on an economically rational criterion such as the overall production costs for SNG or the obtained profit. This choice obviously depends on the economic assumptions for investment depreciation and plant operation defined in Table 2, and is particularly sensitive to the raw material costs and product prices in polygener- 
Table 8: Energy price scenarios and their comparison with the Swiss market.

\begin{tabular}{lllrrrrr}
\hline & & \multicolumn{3}{c}{ Price scenario $^{2}$} & \multicolumn{2}{c}{ CH-market $^{\mathrm{a}}$} \\
Energy vector & \multicolumn{1}{c}{ Unit } & green & mid & low & 1999 & $2008 / 09$ \\
\hline Electricity & $C_{e l}$ & $\$ \mathrm{MWh}^{-1}$ & 180 & 90 & 60 & $90-135$ & $80-160$ \\
Automotive fuel \& SNG & $C_{S N G}$ & $\$ \mathrm{MWh}^{-1}$ & 120 & 60 & 40 & $80-95$ & $130-140$ \\
Industrial heat & $C_{q}$ & $\$ \mathrm{MWh}^{-1}$ & 80 & 40 & 26.6 & $20-35$ & $40-65$ \\
\hline
\end{tabular}

a including tax. Figures for 1999 are from Previdoli and Beck [59], 2008/09 is approximate.

ation applications where multiple competing energy services can be produced or consumed. In addition, the selection of the economic decision criterion to be applied is not trivial, and Section 2.2.2 has shown that the most balanced choice is to consider the maximum acceptable biomass cost to break even $C_{b m, b e}$ (Eq. 11) since it considers the value of all products in an identical way.

In order to highlight the influence of the energy price on the selection of the best plant at a specific scale, the flowsheets that allow for the maximum biomass break-even cost are chosen for the three price scenarios outlined in Table 8. The relatively high, green energy prices are considered as reference and compared to a mid- and low-price scenario for which the economic value of the energy vectors are decreased to $50 \%$ and $33 \%$, respectively. While the former might only be obtained for labelled renewable energy that possibly benefits from tax exemption, the two latter are in the range of current and historic market prices for fossil energy.

Figures 8 and 10 summarise the characteristics of an economically rational process scaling for FICFB and CFB- $\mathrm{O}_{2}$ gasification, respectively. Part (a) shows the maximum break-even costs obtained for a specific process configuration and (b) the chemical efficiency for the overall most profitable flowsheet. Part (c) illustrates its evolution on the Pareto fronts at 5, 20 and $100 \mathrm{MW}$, and Table 9 shows the related decision variables and some performances for green energy prices at small-, mid- and large-scale. Figures 9 and 11 illustrate these configurations at $20 \mathrm{MW}_{t h, b m}$.

With current market prices of 30 to $35 \$ \mathrm{MWh}^{-1}$ for energy wood, the figures indicate that plants can operate profitably if high prices for the produced energy vectors can be obtained, and considerable economies of scale can be expected up to 20 to $30 \mathrm{MW}$ (Figs. 8(a), 10(a)). The maximum biomass costs to break even differ by 10 to $12 \$ \mathrm{MWh}^{-1}$ for the optimal candidate configurations, and the most economic one and its operating conditions change with scale. The variation of the relative distance between the Pareto fronts illustrates that the best process technologies scale considerably different indeed (Figs. 8(c), 10(c)). Membrane separation is a well suited technology for small to medium-sized plants, but suffers from poor economy of scale. In our application, the technology is especially beneficial if heat and power cogeneration is considered since the depleted streams can be efficiently recovery. With increasing plant size, it is yet outperformed by PSA or dedicated large-scale technology such as physical absorption.

As expected, the efficiency of the most economic flowsheet increases with scale since the influence of the investment on the plant economics decreases (Figs. 8(b), 10(b)). The energy prices thereby significantly influence the relation between scale and efficiency since they weight the conversion efficiencies in the economic decision criteria of Eqns (11)-(12). When energy is expensive, renewable SNG, electricity and heat are more precious than heat exchanger area and steam turbines. Very efficient but more expensive flowsheets thus become already economic at small production scales, and the potential for increasing the efficiency with scale appears limited to below 3\%-points. When energy is cheap, the relative influence of the investment cost is more important. Less efficient flowsheets are thus preferred at smaller scale and leave room for increasing the efficiency by up to $9 \%$-points when scaled-up beyond 50 to $100 \mathrm{MW}$. One particularity is observed for FICFB gasification without heat cogeneration, in which the chemical efficiency of the optimal flowsheet for the low-price scenario decreases with scale. This counterintuitive behaviour is explained by the influence of the relative product yields. With the assumed low prices, the relative benefit from selling the cogenerated power decreases and the bulk SNG has a more important influence on the process profitability. A flowsheet with torrefaction becomes optimal since the share of SNG on the plant output is higher. This example shows the difficulty of analysing 

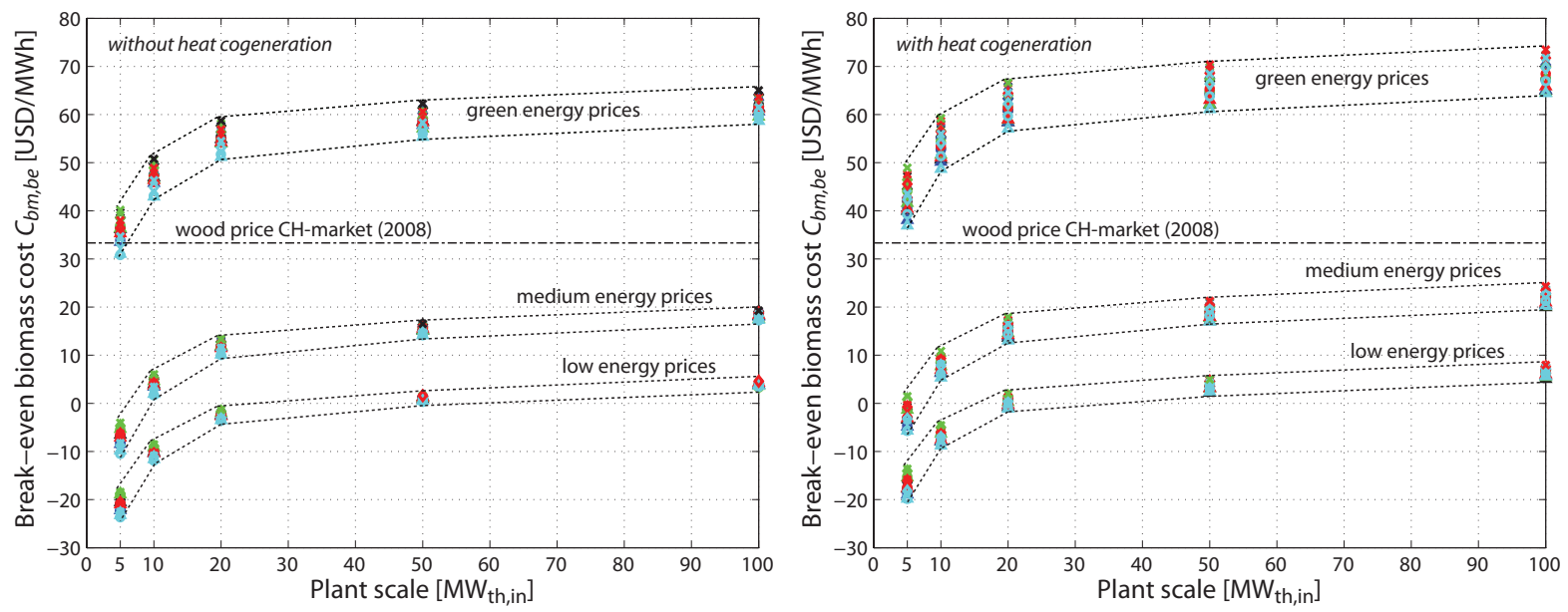

(a) - Maximum biomass break-even costs for each of the candidate configurations.
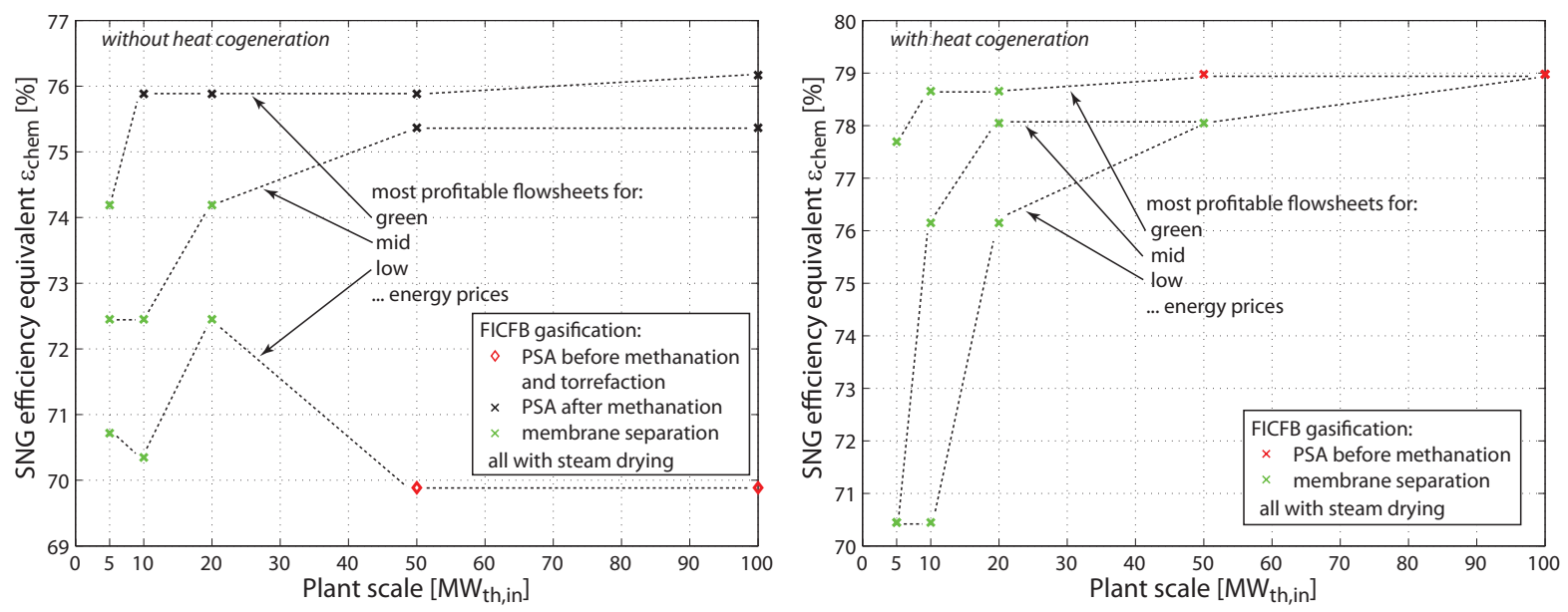

(b) - Process efficiency of the most competitive configurations.
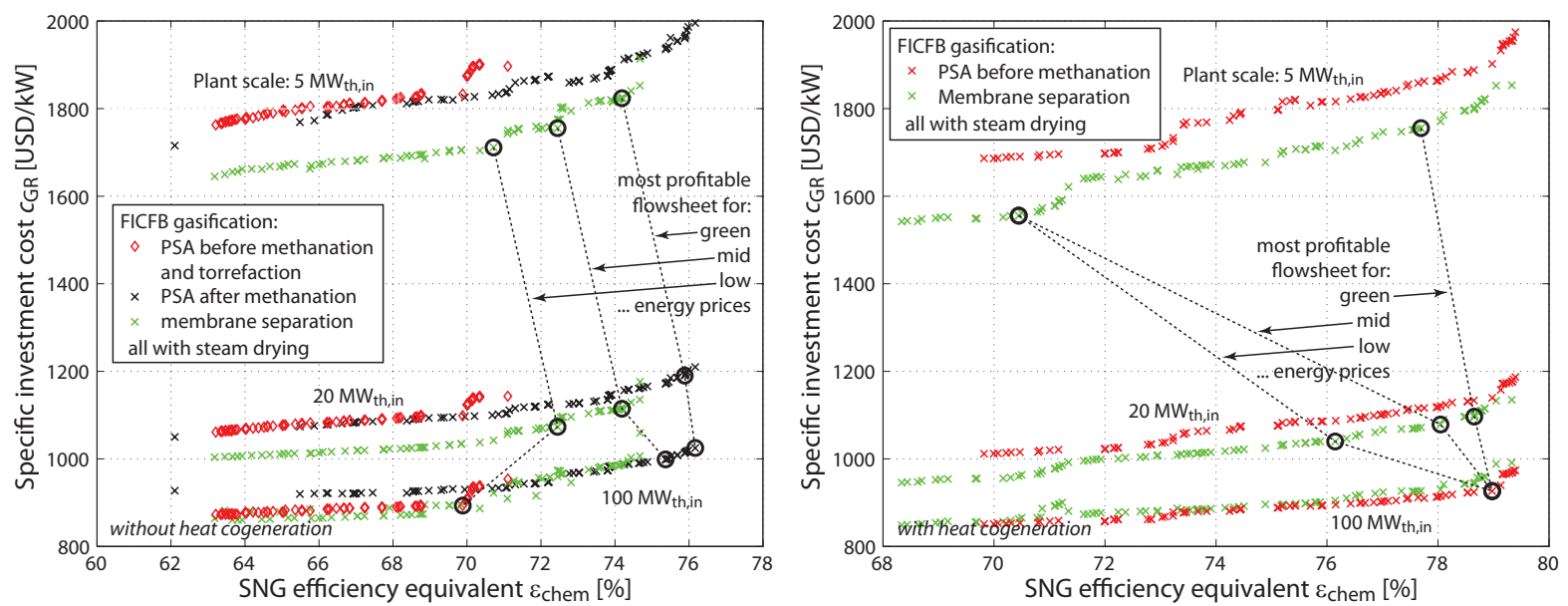

(c) - Evolution of the thermo-economic Pareto-front.

Figure 8: Optimal thermo-economic scaling for FICFB gasification without (left) and with heat cogeneration

polygeneration systems with a single, accumulated efficiency indicator and highlights that only a truly multi-objective approach that considers all product yields individually $[27,28]$ strictly assures optimality in the conceptual synthesis of a specific flowsheet. 


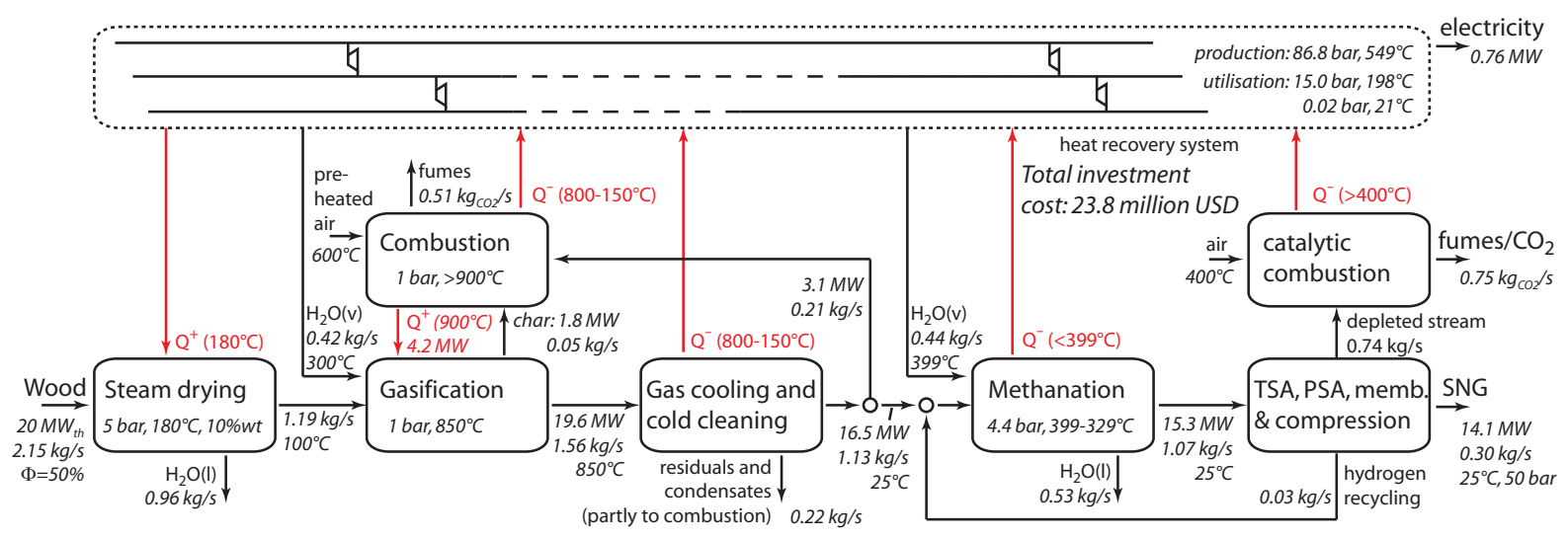

(a) Without heat cogeneration.

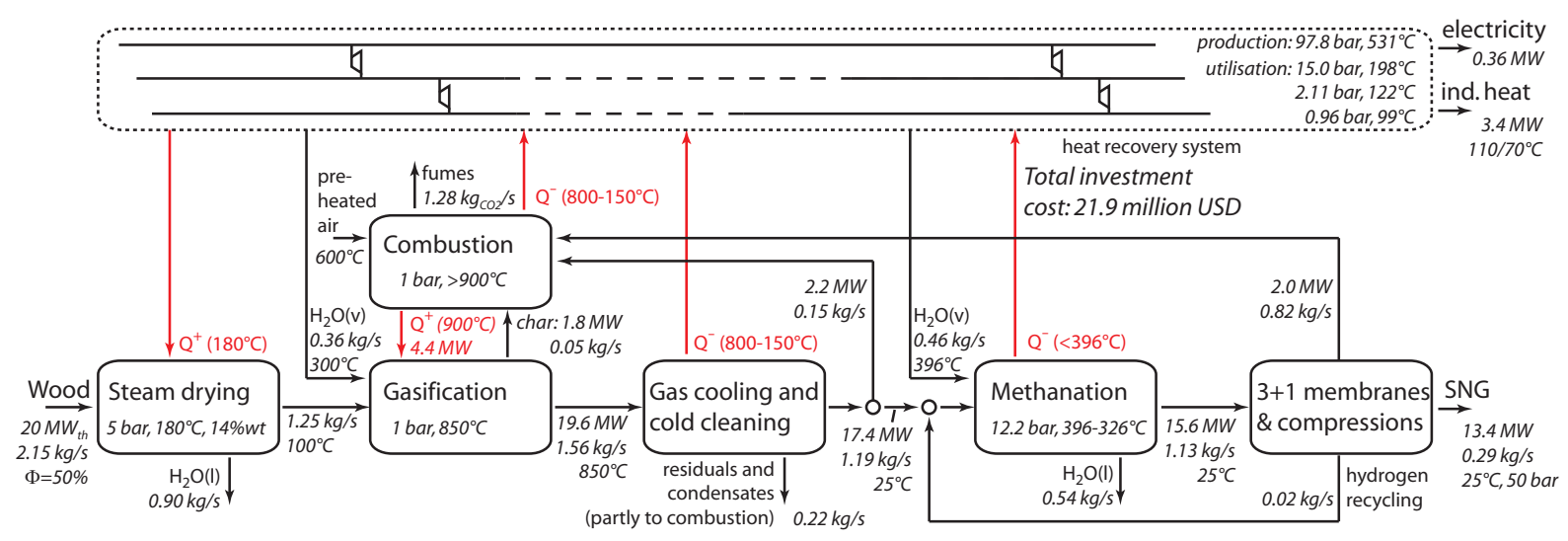

(b) With heat cogeneration.

Figure 9: Schematic flow diagrams for most economical plants at $20 \mathrm{MW}_{t h, b m}$ based on indirectly heated gasification at atmospheric pressure.

\section{Conclusions}

This paper presents a comprehensive analysis of the different processes that can be synthesised to produce SNG from lignocellulosic biomass by gasification and methanation based on technologies that are close to or already available on the market. The comparison is based first on the thermodynamic analysis of the process as a whole. The economic dimension is adressed by separately considering the investment and operating expenses, which are closely related to the efficiency of producing the multiple products.

Coupling a superstructure process model with multi-objective optimisation techniques, a database of Pareto-optimal flowsheets for all potential combinations of the candidate technologies has been generated and allows for identifying the best conceptual flowsheet depending on feedstock availability, local heat cogeneration opportunities, process scale and economic boundary conditions such as energy prices or interest rates. Although limited to the chosen (and extensive) superstructure and the validity of the thermo-economic models for the conceptual process design, this approach generates in-depth understanding of the system interactions and provides an ideal starting point to elaborate detailed flowsheets. The use of a multi-objective optimisation approach in which one of the objectives is independent on the economic conditions allows for systematically generating process alternatives whose performance assessment is less sensitive to the validity of the investment cost estimation since it is only used to compare the solutions among each other.

Compared to the common practice of evaluating some technology scenarios developed by hand, this work demonstrates the prospects of using systematic systems engineering methods for process synthesis in the bioenergy and -fuel sector. As summarised in Table 1, a detailed analysis of the process steps, better process integration and the consideration of alternative technologies [5] have increased the efficiency of 
Table 9: Decision variables and performance of the economically optimal plant configurations.

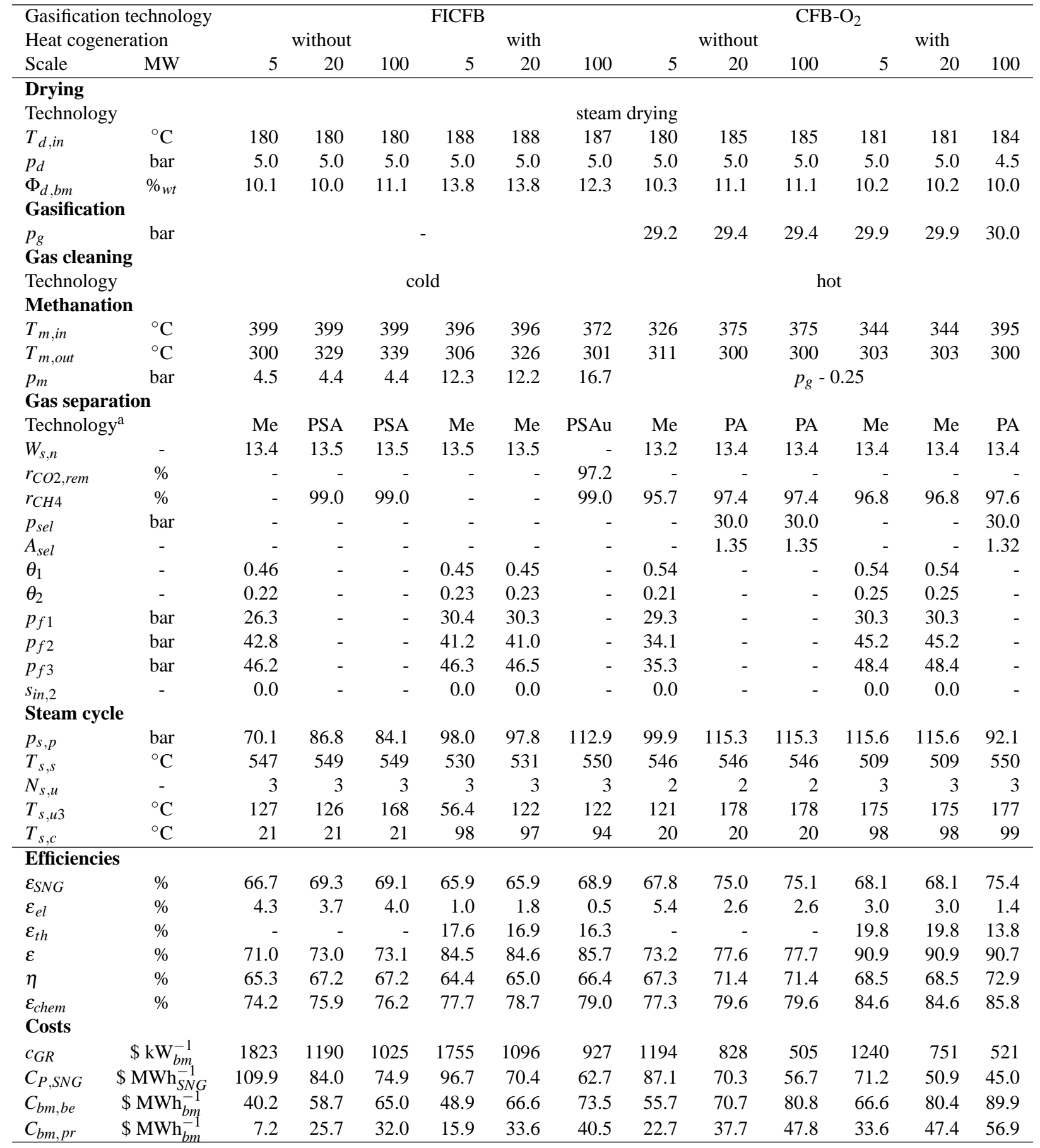

${ }^{a}$ Me: Membrane separation, PSA: Pressure swing adsorption, PSAu: Pressure swing adsorption upstream of methanation, PA: Physical absorption downstream of methanation.

our first flowsheet [16] by 6 to 13\%-points in terms of SNG and 12 to $18 \%$-points in terms of the overall efficiency $\varepsilon_{\text {chem }}$. The thermo-economic optimisation presented in this paper has further revealed the potential for an additional increase by $5 \%$-points of $\varepsilon_{\text {chem }}$ when considering the combined production of SNG and power, or by 8 to $11 \%$-points if industrial heat can also be used on-site. Despite this significant increase of the efficiency, the optimisation of the operating conditions allows for decreasing the investment cost at the same time by 6 to $16 \%$.

Overall, the production of SNG from lignocellulosic biomass by conventional gasification and methanation is an efficient and sustainable option for biomass-to-fuel conversion. Depending on technology, 

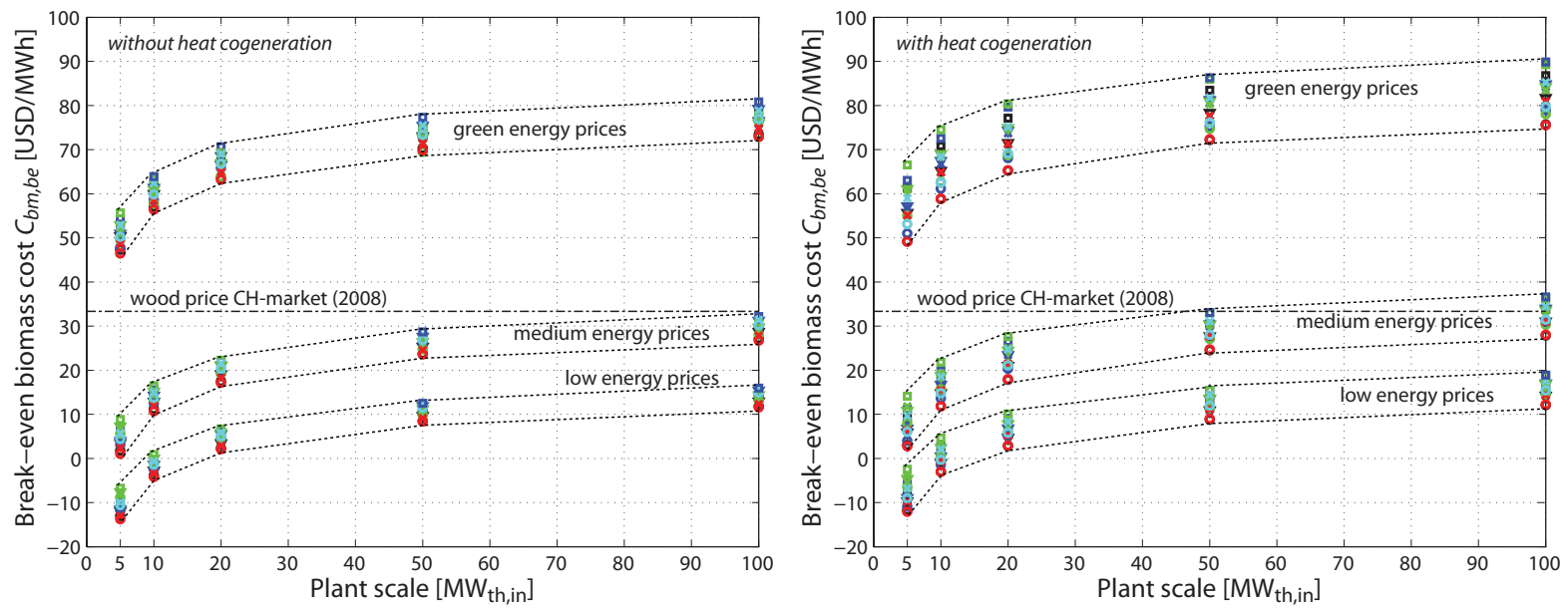

(a) - Maximum biomass break-even costs for each of the candidate configurations.
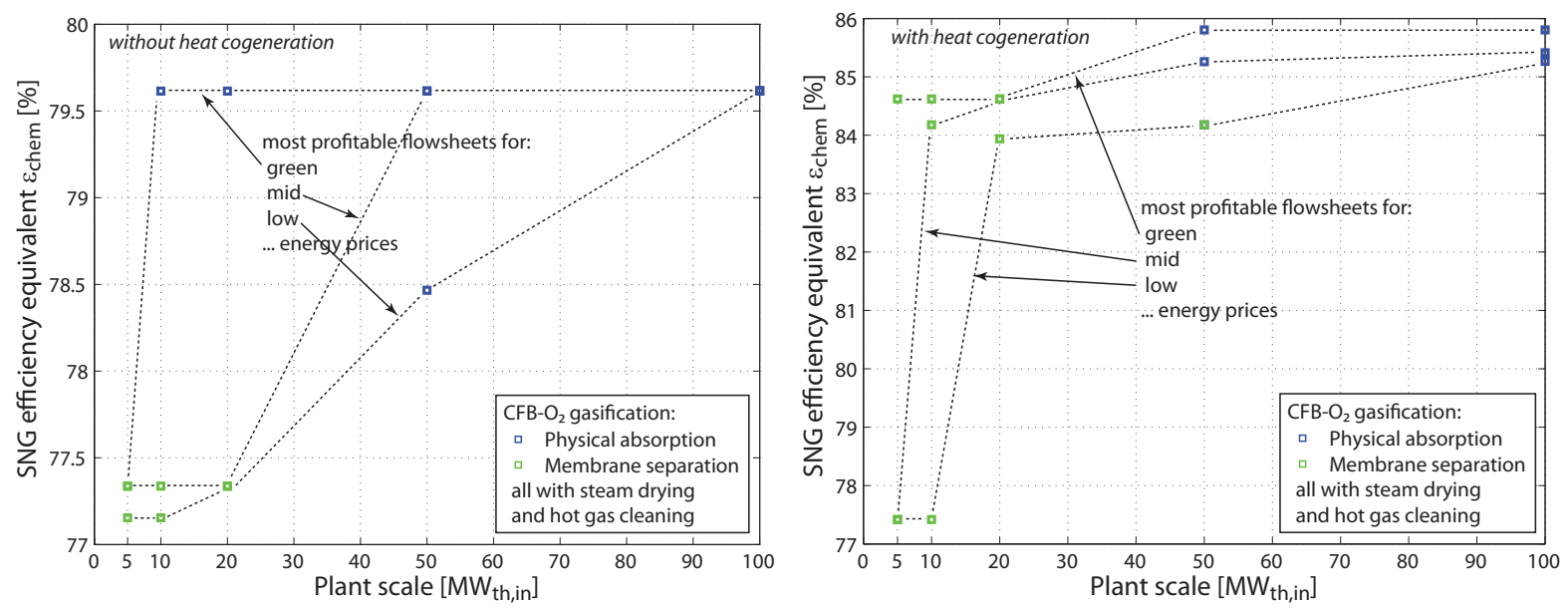

(b) - Process efficiency of the most competitive configurations.
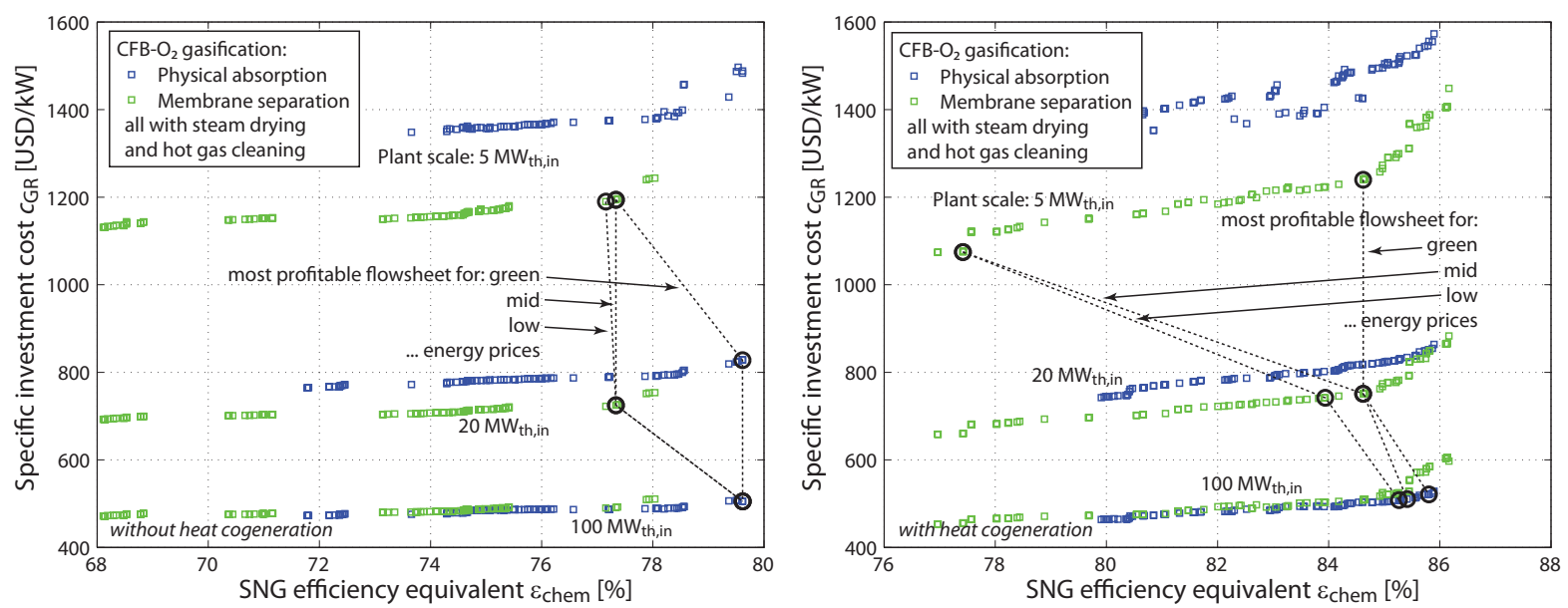

(c) - Evolution of the thermo-economic Pareto-front.

Figure 10: Optimal thermo-economic scaling for CFB-O2 gasification without (left) and with heat cogeneration

process scale and energy prices, the most economic configurations may provide a net fuel yield of 66 to $75 \%$ from wood at $50 \%$ wt humidity based on the lower heating value of the dry substance. The polygeneration of fuel, heat and power allows for a total useful energy yield ranging from 71 to $91 \%$, which corresponds to an equivalent gas yield of 74 to $86 \%$ when substituting the co-products by their equivalent consumption of fossil natural gas. Assuming prices of $80 \$ \mathrm{MWh}^{-1}$ for industrial heat, $120 \$ \mathrm{MWh}^{-1}$ 


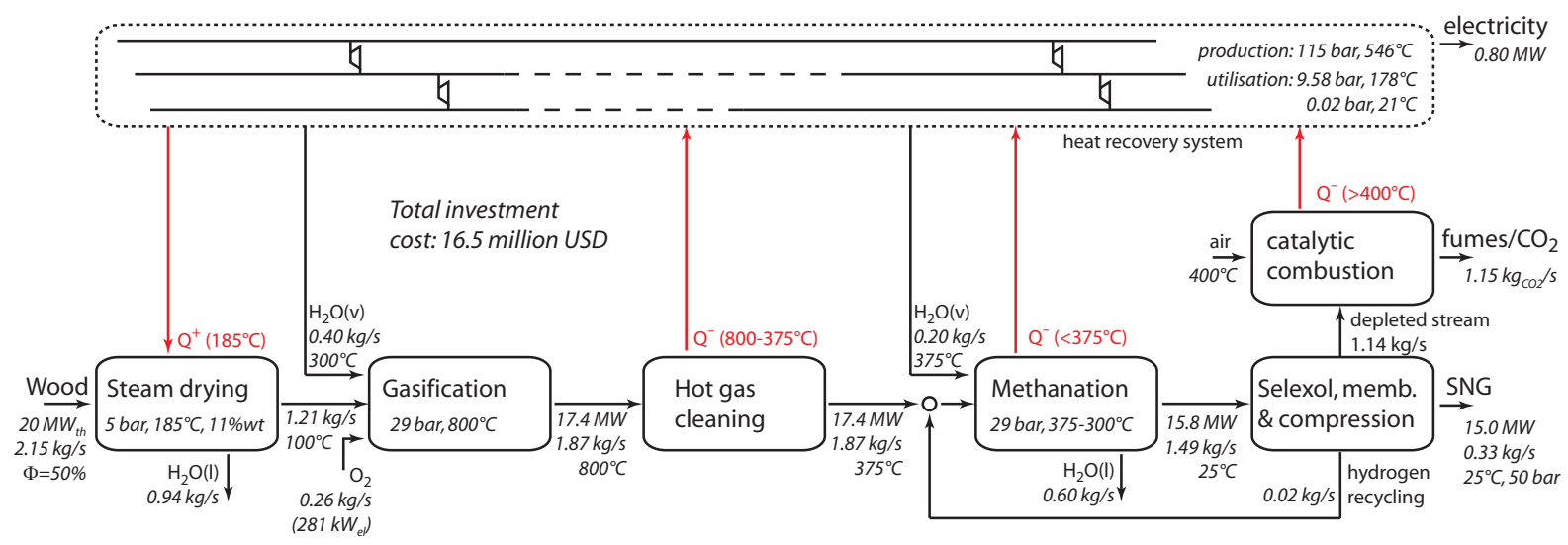

(a) Without heat cogeneration.

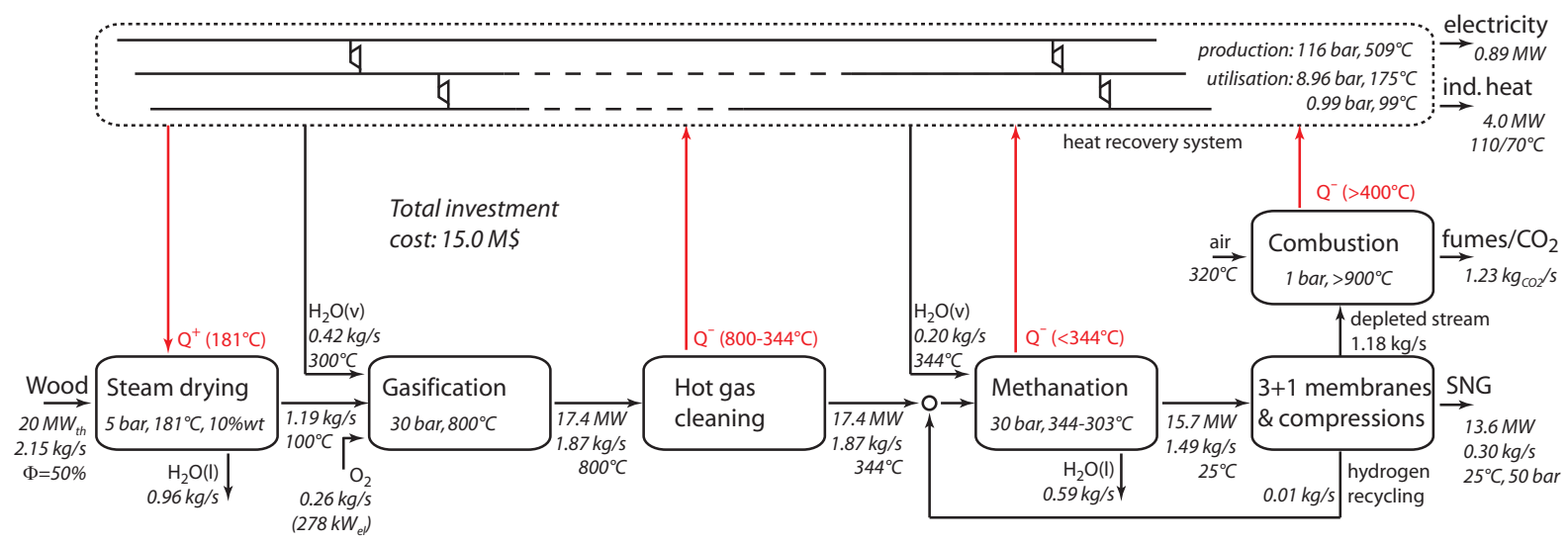

(b) With heat cogeneration.

Figure 11: Schematic flow diagrams for most economical plants at $20 \mathrm{MW}_{t h, b m}$ based on directly heated, pressurised gasification.

for SNG and $180 \$ \mathrm{MWh}^{-1}$ for electricity generated from renewable resources, these efficiencies result in biomass break-even costs of 26 to $47 \$ \mathrm{MWh}_{b m}^{-1}$ at a plant scale of $20 \mathrm{MW}_{t h, b m}$, and as high as $90 \$ \mathrm{MWh}_{b m}^{-1}$ for mature large-scale production above $100 \mathrm{MW}_{t h, b m} .{ }^{5}$

Apart such promising results for SNG, this work highlights the importance of a systematic process design approach based on detailed thermo-economic models, proper mass- and energy-integration, and optimisation. Many of the findings summarised in Table 6 can only be perceived through the application of an integrated systems-approach. Considering a general technology superstructure that includes alternatives to the 'best' flowsheet by intuition, our work has shown that the individually most efficient technologies are not necessarily the best ones from an overall plant perspective, and that the optimal choice can be contrary to intuition. For instance, with respect to the most distictive and critical technology choice, directly heated gasification with oxygen appears to be the better technology for SNG production than indirectly heated gasification, while the opposite is the case for the production of liquid fuels [6]. Such conclusions contest prominent literature [15, 17, 60], in which process integration is not systematically accounted for.

\footnotetext{
${ }^{5}$ If a wood price of $33 \$ \mathrm{MWh}^{-1}$ is assumed, these values correspond to overall production costs for SNG $C_{P, S N G}$ of 51 to $84 \$ \mathrm{MWh}_{S N G}^{-1}$ at $20 \mathrm{MW}_{t h, b m}$ and as low as $45 \$ \mathrm{MWh}_{S N G}^{-1}$ above $100 \mathrm{MW}_{t h, b m}$.
} 


\section{Acknowledgements}

The authors acknowledge funding provided by the Competence Centre for Energy and Mobility (CCEM$\mathrm{CH}$ ), Erdgas Ostschweiz AG, Gasverbund Mittelland AG and Gaznat SA (all Switzerland).

\section{References}

[1] F. Maréchal, D. Favrat, and E. Jochem. Energy in the perspective of the sustainable development: The $2000 \mathrm{~W}$ society challenge. Resources, Conservation and Recycling, 44(3 spec. iss.):245-262, 2005.

[2] B. Steubing, R. Zah, P. Waeger, and C. Ludwig. Bioenergy in Switzerland: Assessing the domestic sustainable biomass potential. Renewable and Sustainable Energy Reviews, 14(8):2256-2265, 2010. doi: 10.1016/j.rser.2010.03.036.

[3] Jorn P. W. Scharlemann and William F. Laurance. How green are biofuels? Science, 319(5859):43-44, 2008.

[4] David Tilman, Robert Socolow, Jonathan A. Foley, Jason Hill, Eric Larson, Lee Lynd, Stephen Pacala, John Reilly, Tim Searchinger, Chris Somerville, and Robert Williams. Beneficial biofuels - the food, energy, and environment trilemma. Science, 325(5938):270-271, 2009.

[5] Martin Gassner and François Maréchal. Thermo-economic process model for thermochemical production of Synthetic Natural Gas (SNG) from lignocellulosic biomass. Biomass and Bioenergy, 33:1587-1604, 2009. doi: 10.1016/j.biombioe.2009.08.004.

[6] Laurence Tock, Martin Gassner, and François Maréchal. Thermo-economic process model for thermochemical production of liquid fuels from lignocellulosic biomass. Biomass and Bioenergy, 34:1838-1854, 2010.

[7] R. Edwards, J-C. Griesemann, J-F. Larivé, and V. Mathieu. Well-to-wheels analysis of future automotive fuels and powertrains in the european context. well-to-wheels report. EUCAR/CONCAWE, January 2004. Version $1 \mathrm{~b}$.

[8] W. Zhang. Automotive fuels from biomass via gasification. Fuel Processing Technology, 91(8):866-876, 2010.

[9] Rakesh Agrawal and Navneet R. Singh. Solar energy to biofuels. Annual Review of Chemical and Biomolecular Engineering, 1(1):343-364, 2010.

[10] Martin Gassner, Renato Baciocchi, François Maréchal, and Marco Mazzotti. Integrated design of a gas separation system for the upgrade of crude SNG with membranes. Chemical Engineering and Processing: Process Intensification, 48: 1391-1404, 2009.

[11] J. Kopyscinski, T. J. Schildhauer, and S. M. A. Biollaz. Production of synthetic natural gas (SNG) from coal and dry biomass - a technology review from 1950 to 2009. Fuel, 89(8):1763-1783, 2010.

[12] M. C. Seemann, T. J. Schildhauer, and S. M. A. Biollaz. Fluidized bed methanation of wood-derived producer gas for the production of synthetic natural gas. Industrial and Engineering Chemistry Research, 49(15):7034-7038, 2010.

[13] S. Biollaz, T. Schildhauer, D. Ulrich, H. Tremmel, R. Rauch, and M. Koch. Status report of the demonstration of BioSNG production on a $1 \mathrm{MW}$ scale in Güssing. In 17th European Biomass Conference and Exhibition, Hamburg, Germany, 2009.

[14] H. Hofbauer, R. Rauch, G. Löeffler, S. Kaiser, E. Fercher, and H. Tremmel. Six years experience with the FICFBgasification process. In Proceedings of the 12th European Conference and Technology Exhibition on Biomass for Energy, Industry and Climate Protection, Amsterdam, Netherlands, 2002.

[15] M. Mozaffarian and R. W. R. Zwart. Feasibility of biomass/waste-related SNG production technologies. Technical report, ECN, Petten, 2003.

[16] Alexis Duret, Claude Friedli, and François Maréchal. Process design of Synthetic Natural Gas (SNG) production using wood gasification. Journal of Cleaner Production, 13:1434-1446, 2005.

[17] C. M. Van der Meijden, H. J. Veringa, and L. P. L. M. Rabou. The production of synthetic natural gas (SNG): A comparison of three wood gasification systems for energy balance and overall efficiency. Biomass and Bioenergy, 34(3): 302-311, 2010.

[18] M. Juraščík, A. Sues, and K. J. Ptasinski. Exergetic evaluation and improvement of biomass-to-synthetic natural gas conversion. Energy and Environmental Science, 2(7):791-801, 2009. 
[19] S. Heyne, H. Thunman, and S. Harvey. Extending existing CHP plants for SNG production - a process integration study. International Journal of Energy Research, page in press, 2011. doi: 10.1002/er.1828.

[20] E. Fahlén and E. O. Ahlgren. Assessment of integration of different biomass gasification alternatives in a district-heating system. Energy, 34(12):2184-2195, 2009.

[21] K. Difs, E. Wetterlund, L. Trygg, and M. Söderström. Biomass gasification opportunities in a district heating system. Biomass and Bioenergy, 34(5):637-651, 2010.

[22] R. Toonssen, N. Woudstra, and A. H. M. Verkooijen. Decentralized generation of electricity with solid oxide fuel cells from centrally converted biomass. International Journal of Hydrogen Energy, 35(14):7594-7607, 2010.

[23] R. Felder and R. Dones. Evaluation of ecological impacts of synthetic natural gas from wood used in current heating and car systems. Biomass and Bioenergy, 31(6):403-415, 2007.

[24] R. Zah, H. Böni, M. Gauch, R. Hischier, M. Lehmann, and P. Wäger. Oekobilanz von Energieprodukten: Oekologische Bewertung von Biotreibstoffen. Technical report, Swiss Federal Laboratories for Materials Testing and Research (EMPA), Switzerland, 2007.

[25] N. Jungbluth, M. Chudacoff, A. Dauriat, F. Dinkel, G. Doka, M.F. Emmenegger, E. Gnansounou, N. Kljun, K. Schleiss, M. Spielmann, C. Stettler, and J. Sutter. Life Cycle Inventories of Bioenergy. Data v2.2, Ecoinvent Report No. 17, Swiss Centre for Life Cycle Inventories, Dübendorf, Switzerland, 2007. www.ecoinvent.ch (last visited 10/2010).

[26] B. Steubing, R. Zah, and C. Ludwig. Life cycle assessment of SNG from wood for heating, electricity, and transportation. Biomass and Bioenergy, 35:2950-2960, 2011.

[27] Martin Gassner and François Maréchal. Methodology for the optimal thermo-economic, multi-objective design of thermochemical fuel production from biomass. Computers and Chemical Engineering, 33:769-781, 2009.

[28] Martin Gassner and François Maréchal. Combined mass and energy integration in process design at the example of membrane-based gas separation systems. Computers and Chemical Engineering, 34(12):2033-2042, 2010. Invited publication for the special edition of PSE 2009.

[29] Martin Gassner and François Maréchal. Thermodynamic comparison of the FICFB and Viking gasification concepts. Energy, 34:1744-1753, 2009. doi: 10.1016/j.energy.2009.05.011. Invited publication for the special edition of PRES 2008 .

[30] Martin Gassner and François Maréchal. Thermo-economic optimisation of the integration of electrolysis in synthetical natural gas production from wood. Energy, 33:189-198, 2008. Invited publication for the special edition of ECOS 2006.

[31] Léda Gerber, Martin Gassner, and François Maréchal. Systematic integration of LCA in process systems design: Application to combined fuel and electricity production from lignocellulosic biomass. Computers and Chemical Engineering, 35:1265-1280, 2011.

[32] Belsim SA. Vali IV. www.belsim.com, last visited 04/2009.

[33] G. D. Ulrich and P. T. Vasudevan. Chemical engineering process design and economics. A practical guide. Process publishing, New Hampshire, 2nd edition, 2004.

[34] Werner Boie. Fuel technology calculations. Energietechnik, 3:309-316, 1953.

[35] J. Szargut and T. Styrylska. Angenäherte Bestimmung der Exergie von Brennstoffen. Brennstoff-Wärme-Kraft, 16:589636, 1964.

[36] Carlo N. Hamelinck, André P. C. Faaij, Herman den Uil, and Harold Boerrigter. Production of FT transportation fuels from biomass; technical options, process analysis and optimisation, and development potential. Technical report, ECN, Petten, Netherlands, 2003.

[37] Martin Gassner. Process design methodology for thermochemical production of fuels from biomass. Application to the production of Synthetic Natural Gas from lignocellulosic resources. PhD thesis, EPFL, 2010.

[38] D. Favrat, F. Marechal, and O. Epelly. The challenge of introducing an exergy indicator in a local law on energy. Energy, 33(2):130-136, 2008.

[39] Mark J. Kirschner. Oxygen. In Ullmann's encyclopedia of industrial chemistry. Wiley-VCH, 7th edition, 2009.

[40] A. Toffolo and A. Lazzaretto. Evolutionary algorithms for multi-objective energetic and economic optimization in thermal system design. Energy, 27(6):549-567, 2002. 
[41] A. Lazzaretto and A. Toffolo. Energy, economy and environment as objectives in multi-criterion optimization of thermal systems design. Energy, 29(8):1139-1157, 2004.

[42] H. Sayyaadi. Multi-objective approach in thermoenvironomic optimization of a benchmark cogeneration system. Applied Energy, 86(6):867-879, 2009.

[43] A. Molyneaux, G. Leyland, and D. Favrat. Environomic multi-objective optimisation of a district heating network considering centralized and decentralized heat pumps. Energy, 35(2):751-758, 2010.

[44] Francois Maréchal, Francesca Palazzi, Julien Godat, and Daniel Favrat. Thermo-economic modelling and optimisation of fuel cell systems. Fuel Cells, 5:5-24, 2005.

[45] N. Autissier, F. Palazzi, F. Marechal, J. van Herle, and D. Favrat. Thermo-economic optimization of a solid oxide fuel cell, gas turbine hybrid system. Journal of Fuel Cell Science and Technology, 4(2):123-129, 2007.

[46] H. Li, F. Marchal, M. Burer, and D. Favrat. Multi-objective optimization of an advanced combined cycle power plant including CO2 separation options. Energy, 31(15):3117-3134, 2006.

[47] David Brown, Martin Gassner, Tetsuo Fuchino, and François Maréchal. Thermo-economic analysis for the optimal conceptual design of biomass gasification energy conversion systems. Applied Thermal Engineering, 29:2137-2152, 2009.

[48] P. Liu, E. N. Pistikopoulos, and Z. Li. A multi-objective optimization approach to polygeneration energy systems design. AICHE Journal, 56(5):1218-1234, 2010.

[49] I. E. Grossmann and G. Guillén-Gosálbez. Scope for the application of mathematical programming techniques in the synthesis and planning of sustainable processes. Computers and Chemical Engineering, 34(9):1365-1376, 2010.

[50] Y. Chen, T.A. Adams II, and P.I. Barton. Optimal design and operation of static energy polygeneration systems. Industrial \& Engineering Chemistry Research, pages in press, doi: 10.1021/ie101568v, 2010. doi: 10.1021/ie101568v.

[51] Adam Molyneaux, Daniel Favrat, and Geoff Leyland. A new clustering evolutionary multi-objective optimisation technique. In 3rd International Symposium on Adaptive Systems, Institute of Cybernetics, Mathematics and Physics, pages $41-47$.

[52] U. Henriksen, J. Ahrenfeldt, T.K. Jensen, B. Gøbel, J.D. Bentzen, C. Hindsgaul, and L.H. Sørensen. The design, construction and operation of a $75 \mathrm{~kW}$ two-stage gasifier. Energy, 31:1542-1553, 2006.

[53] Haldor Topsøe A/S. From solid fuels to substitute natural gas (SNG) using TREMP. www.topsoe.com, 2009.

[54] B. Kalitventzeff, F. Maréchal, and H. Closon. Better solutions for process sustainability through better insight in process energy integration. Applied Thermal Engineering, 21(13-14):1349-1368, 2001.

[55] Martin Gassner, Frédéric Vogel, Georges Heyen, and François Maréchal. Optimal process design for the polygeneration of SNG, power and heat by hydrothermal gasification of waste biomass: Thermo-economic process modelling and integration. Energy and Environmental Science, 4:1726-1741, 2011.

[56] Martin Gassner, Frédéric Vogel, Georges Heyen, and François Maréchal. Optimal process design for the polygeneration of SNG, power and heat by hydrothermal gasification of waste biomass: Process optimisation for selected substrates. Energy and Environmental Science, 4:1742-1758, 2011.

[57] E. Bernier, R. Samson, L. Gerber, and F. Marechal. Life-cycle environomic optimisation of NGCC plant with biogenic fuel and $\mathrm{CO} 2$ capture. In 8th World Congress of Chemical Engineering: Incorporating the 59th Canadian Chemical Engineering Conference and the 24th Interamerican Congress of Chemical Engineering, 2009.

[58] Bernhard Steubing, Isabel Ballmer, Léda Gerber, Fran\{ccois Maréchal, Rainer Zah, and Christian Ludwig. An environmental optimization model for bioenergy plant sizes and locations for the case of wood-derived SNG in Switzerland. In World Renewable Energy Congress, 2011.

[59] Pascal Previdoli and Martin Beck. Vergleich der Energiepreise in verschiedenen OECD-Ländern. Bundesamt für Energie, 2001. www.bfe.ch (last visited 11/2009).

[60] J. A. Michiel Tijmensen, André P. C. Faaij, Carlo N. Hamelinck, and Martijn R. M. van Hardeveld. Exploration of the possibilities for production of Fischer Tropsch liquids and power via biomass gasification. Biomass and Bioenergy, 23: $129-152,2002$. 